\title{
Aqueous Phosphoric Acid as a Mild Reagent for Deprotection of tert-Butyl Carbamates, Esters and Ethers
}

Bryan Li, ${ }^{*}$ Martin Berliner, Richard Buzon, Charles K.-F. Chiu, Stephen T. Colgan, Takushi Kaneko, Nandell Keene, William Kissel ${ }^{\mathrm{a}}$, Tung Le, Kyle R. Leeman, Brian Marquez, Ronald Morris, Lisa Newell, Silke Wunderwald, Michael Witt, John Weaver, Zhijun Zhang, and Zhongli Zhang

Groton Laboratories, Pfizer Global Research and Development, Groton, CT 06340, USA

\section{Supporting Information}

I. General Experimental

II. Characterization of Compounds in Table 1

III. Characterization of Compounds in Table 2

IV. Characterization of Compounds in Table 3

V. Characterization of Compound 4
S1

S2

S15

$\mathrm{S} 22$

S28

General: NMR spectra were recorded at $400 \mathrm{MHz}$ unless specified otherwise. Chemical shifts are reported in part per million ( $\mathrm{ppm}$ ) with TMS as an internal standard. LCMS was recorded using API-ES ionization mode. Reagents and solvents were obtained from commercial sources and used without further purifications. Achiral HPLC analyses were carried out using a stablebond cyano $(\mathrm{SB}-\mathrm{CN})$ column $(4.6 \mathrm{~mm} \times 250 \mathrm{~mm})$ with acetonitrile: $0.2 \%$ perchloric acid aqueous buffer (20/80 or 40/60) as mobile phase $(2 \mathrm{~mL} / \mathrm{min})$ and detection at $210 \mathrm{~nm}$ wavelength. Chiral HPLC methods were used for the assays: AD-H column, $4.6 \times 250 \mathrm{~mm}$, hexane:ethanol:diethylamine (90/10/0.2) mobile phase, $1.5 \mathrm{~mL} / \mathrm{min} .35^{\circ} \mathrm{C}, 210$ or $225 \mathrm{~nm}$.

\footnotetext{
* To whom correspondence should be addressed: Email: bryan.li@pfizer.com; Fax: 1-860-715-7305

a Ann Arbor Laboratories, Pfizer Global R\&D, Ann Arbor, MI 48105, USA.
} 
One dimensional and extensive 2D NMR experiments were performed for the assignment of the proton and carbon spectra. Electrospray (ESP) mass spectrometry, with a flow injection sample introduction technique, along with tandem mass spectrometry was performed.

The preparations of products in Tables 1, 2 and 3 followed general procedures in the Experimental Section. All products were characterized by NMR and MS, in addition the products were shown to co-elute with authentic samples either from commercial sources or obtained from other established methods.

\section{Characterization of Products in Table 1.}

\begin{tabular}{|c|c|c|}
\hline Entry & Product & Characterization \\
\hline 1 & Methyl L-phenylalaninate & $\begin{array}{l}{ }^{1} \mathrm{H} \text { NMR }\left(\mathrm{DMSO}-\mathrm{d}_{6}\right) \delta 7.28-7.14(\mathrm{~m}, 5 \mathrm{H}), 3.58- \\
3.51(\mathrm{~m}, 4 \mathrm{H}), 2.87-2.72(\mathrm{~m}, 2 \mathrm{H})\end{array}$ \\
\hline 2 & 1-Benzyl L-aspartate & $\begin{array}{l}{ }^{1} \mathrm{H} \text { NMR }\left(\text { DMSO-d }_{6}\right) \delta 7.36-7.28(\mathrm{~m}, 5 \mathrm{H}), 5.10 \\
(\mathrm{~s}, 2 \mathrm{H}), 3.76-3.72(\mathrm{~m}, 1 \mathrm{H}), 2.57-2.39(\mathrm{~m}, 2 \mathrm{H}) .\end{array}$ \\
\hline 3 & $\begin{array}{l}\text { (9-Fluorenylmethoxycarbonyl)- } \\
\text { L-histidine }\end{array}$ & $\begin{array}{l}{ }^{1} \mathrm{H} \text { NMR }\left(\text { DMSO-d }_{6}\right) \delta 8.87-7.22(\mathrm{~m}, 9 \mathrm{H}), 6.82 \\
(\mathrm{~s}, 1 \mathrm{H}), 4.25-4.05(\mathrm{~m}, 5 \mathrm{H}), 3.30-2.88(\mathrm{~m}, 2 \mathrm{H})\end{array}$ \\
\hline 4 & $\begin{array}{l}\mathrm{N}-\delta \text {-Benzyloxycarbonyl-D- } \\
\text { ornithine }\end{array}$ & $\begin{array}{l}{ }^{1} \mathrm{H} \text { NMR }\left(\mathrm{DMSO}^{\left.-\mathrm{d}_{6}\right)} \delta 7.48-7.25(\mathrm{~m}, 5 \mathrm{H}), 4.97\right. \\
(\mathrm{s}, 2 \mathrm{H}), 3.07(\mathrm{t}, 2 \mathrm{H}, \mathrm{J}=6.4 \mathrm{~Hz}), 2.98-2,81(\mathrm{~m}, \\
2 \mathrm{H}), 1,73-1.376(\mathrm{~m}, 4 \mathrm{H})\end{array}$ \\
\hline 5 & Methyl L-valinate & $\begin{array}{l}{ }^{1} \mathrm{HNMR}\left(\mathrm{DMSO}_{\mathrm{N}} \mathrm{d}_{6}\right) \delta 3.61(\mathrm{~s}, 3 \mathrm{H}), 3.23(\mathrm{~d}, 1 \mathrm{H}, \mathrm{J} \\
=5.4 \mathrm{~Hz}), 1.97-1.82(\mathrm{~m}, 1 \mathrm{H}), 0.86-0.80(\mathrm{~m}, \\
6 \mathrm{H}) .\end{array}$ \\
\hline
\end{tabular}


6

Methyl (3R,4R)-4-[3-oxo-3(6-methoxyquinolin-4yl)propyl]piperidine-3carboxylate
(3R,5S)-5-((S)-1-amino-2-(3fluorophenyl)ethyl)-3-(3hydroxy-3-methylbutyl)dihydrofuran-2(3H)-one
9

10
${ }^{1} \mathrm{HNMR}\left(\mathrm{DMSO}-\mathrm{d}_{6}\right) \delta 9.08(\mathrm{~d}, 1 \mathrm{H}, \mathrm{J}=2.8 \mathrm{~Hz})$, $8.37(\mathrm{~d}, 1 \mathrm{H}, \mathrm{J}=4.5 \mathrm{~Hz}), 8.21(\mathrm{~d}, 1 \mathrm{H}, \quad \mathrm{J}=2.8 \mathrm{~Hz})$, $7.75(\mathrm{dd}, 1 \mathrm{H}, \mathrm{J}=4.5$ and $2.8 \mathrm{~Hz}), 7.64(\mathrm{~d}, 1 \mathrm{H}, \mathrm{J}=$ $2.8 \mathrm{~Hz}), 3.91(\mathrm{~s}, 3 \mathrm{H}), 3.62(\mathrm{~s}, 3 \mathrm{H}), 3.39-2.83(\mathrm{~m}$, $7 \mathrm{H}), 2.20-2.04(\mathrm{~m}, 1 \mathrm{H}), 1.94-1.55(\mathrm{~m}, 5 \mathrm{H})$. ${ }^{1} \mathrm{H}$ NMR $\left(\mathrm{CDCl}_{3}, 400 \mathrm{MHz}\right) \delta 7.20-7.36(\mathrm{~m}, 1 \mathrm{H})$, 6.85-7.01 (m, 3H), 4.36-4.44 (m, 1H), 2.58-3.05 $(\mathrm{m}, 4 \mathrm{H}), 2.25-2.40(\mathrm{~m}, 1 \mathrm{H}), 1.80-2.04(\mathrm{~m}, 2 \mathrm{H})$, 1.37-1.64 (m, 6H), $1.21(\mathrm{~s}, 3 \mathrm{H}), 1.22(\mathrm{~s}, 3 \mathrm{H}) ;{ }^{13} \mathrm{C}$ NMR $\left(\mathrm{CDCl}_{3}, 400 \mathrm{MHz}\right) \delta 179.6,164.1,161.8$, 140.6, 130.2, 130.1, 124.9, 124.8, 116.1, 115.9, 113.7, 113.5, 80.9, 70.5, 56.4, 40.8, 39.8, 30.8, 29.5, 29.0, 26.2, 14.1. ${ }^{13} \mathrm{C} \mathrm{NMR}\left(\mathrm{CDCl}_{3}, 400\right.$ MHz) $\delta 179.6,164.1,161.8,140.6,130.2,130.1$, 124.9, 124.8, 116.1, 115.9, 113.7, 113.5, 80.9, $70.5,56.4,40.8,39.8,30.8,29.5,29.0,26.2,14.1$.

4-((tert-

8 butyldimethylsilyloxy)methyl)

${ }^{1} \mathrm{H}$ NMR (DMSO-d $) \delta 6.02(1 \mathrm{H}$, br s), 3.09 (d, 2H, $\mathrm{J}=6.8 \mathrm{~Hz}), 3.09-3.02(2 \mathrm{H}, \mathrm{m}), 2.75(2 \mathrm{H}, \mathrm{t}, \mathrm{J}=7.3$

piperidine $\mathrm{Hz}), 1.78-1.09$ (7H, m), 0.88 (s, 9H), -0.51 (s, 6H)

3-amino-1-

${ }^{1} \mathrm{H}$ NMR (DMSO-d $\left.{ }_{6}\right) \delta 7.39-7.11(\mathrm{~m}, 10 \mathrm{H}), 4.79$ (br s, 2H), 4.32 (s, 1H), $3.44-3.38(\mathrm{~m}, 1 \mathrm{H}), 3.31$ $(\mathrm{dd}, 1 \mathrm{H}, \mathrm{J}=4.5$ and $6.2 \mathrm{~Hz}), 2.59(\mathrm{dd}, 1 \mathrm{~J}, \mathrm{~J}=4.5$ and $6.2 \mathrm{~Hz}$ )

${ }^{1} \mathrm{H}$ NMR $\left(\mathrm{CDCl}_{3}\right) \delta$ 7.23-7.18 (2H, m), 7.11-7.08 $(2 \mathrm{H}, \mathrm{m}), 4.58(2 \mathrm{H}, \mathrm{s}), 1.95(2 \mathrm{H}, \mathrm{dt}, \mathrm{J}=7.2$ and 2.5 $\mathrm{Hz}), 1.19-1.18$ (2H, m). 
Supporting Information

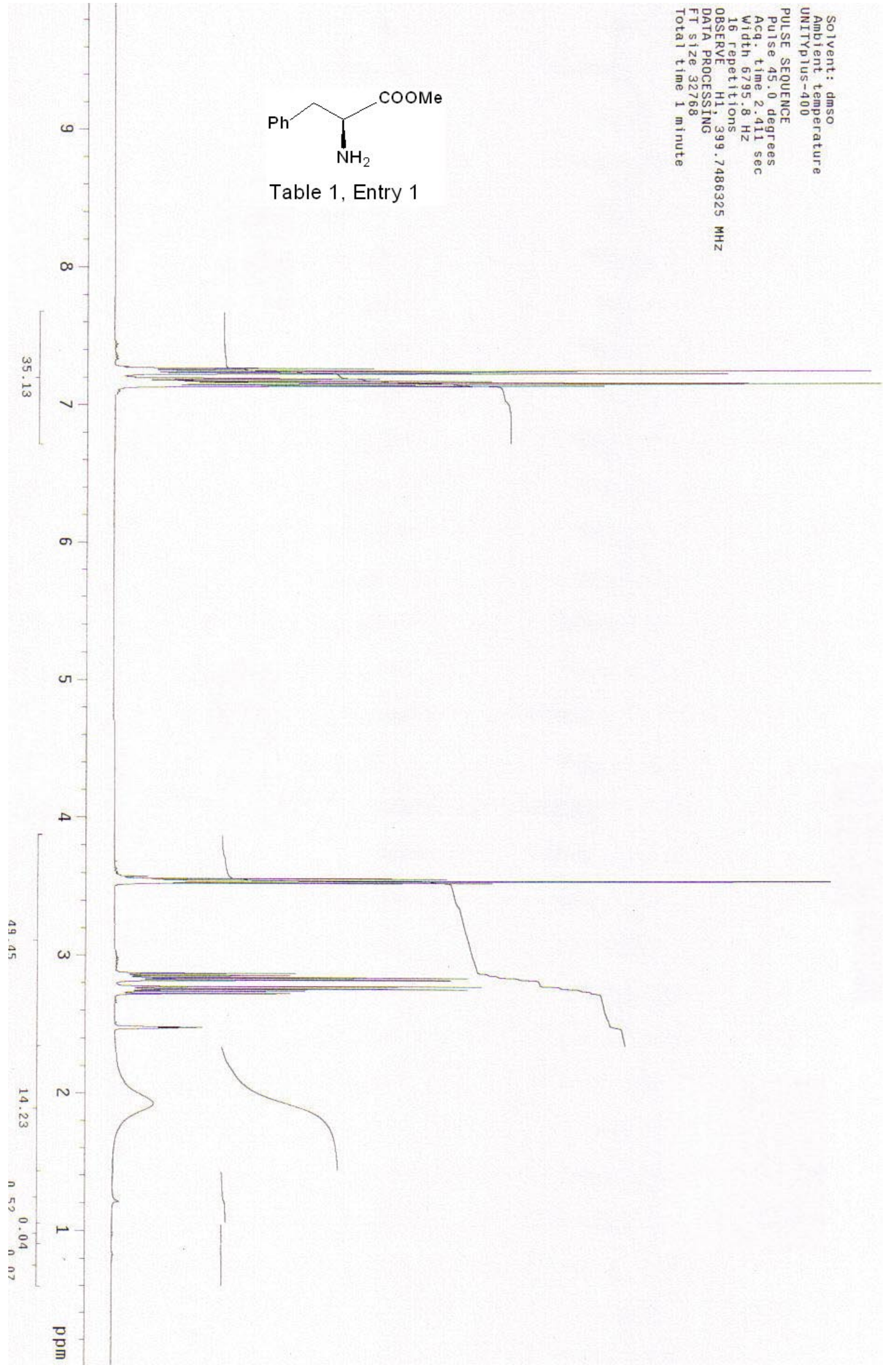




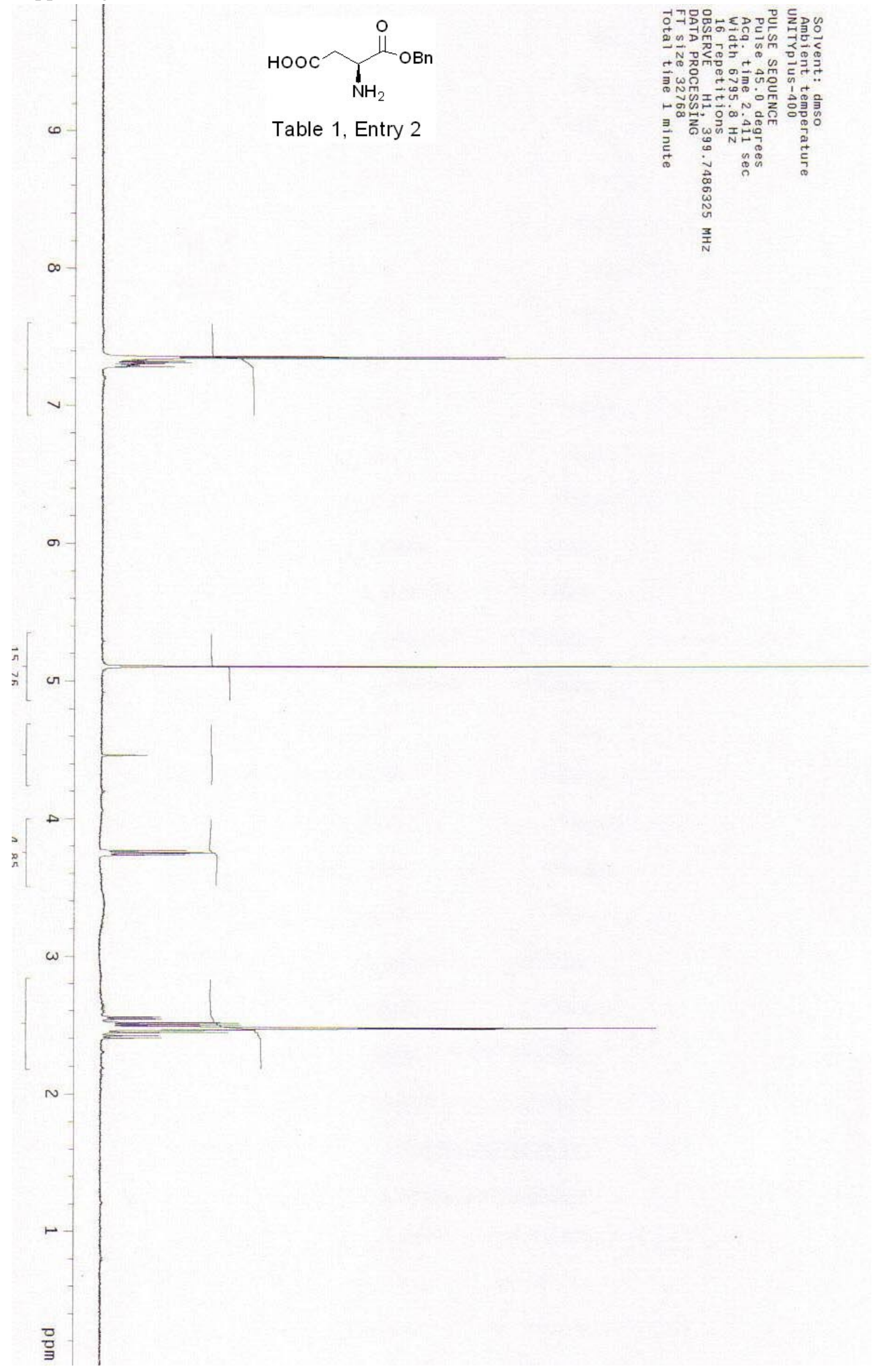


Supporting Information

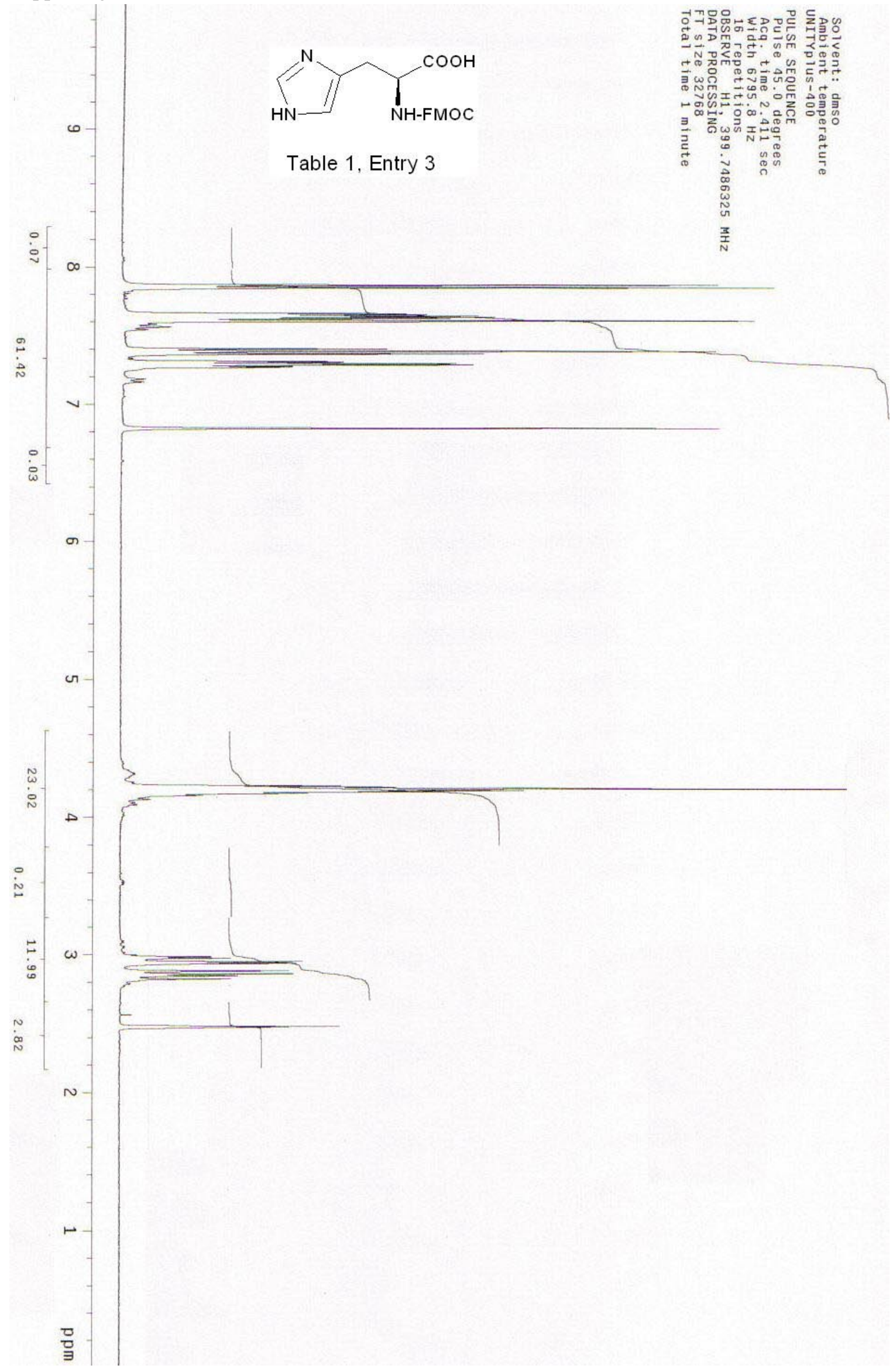


Supporting Information

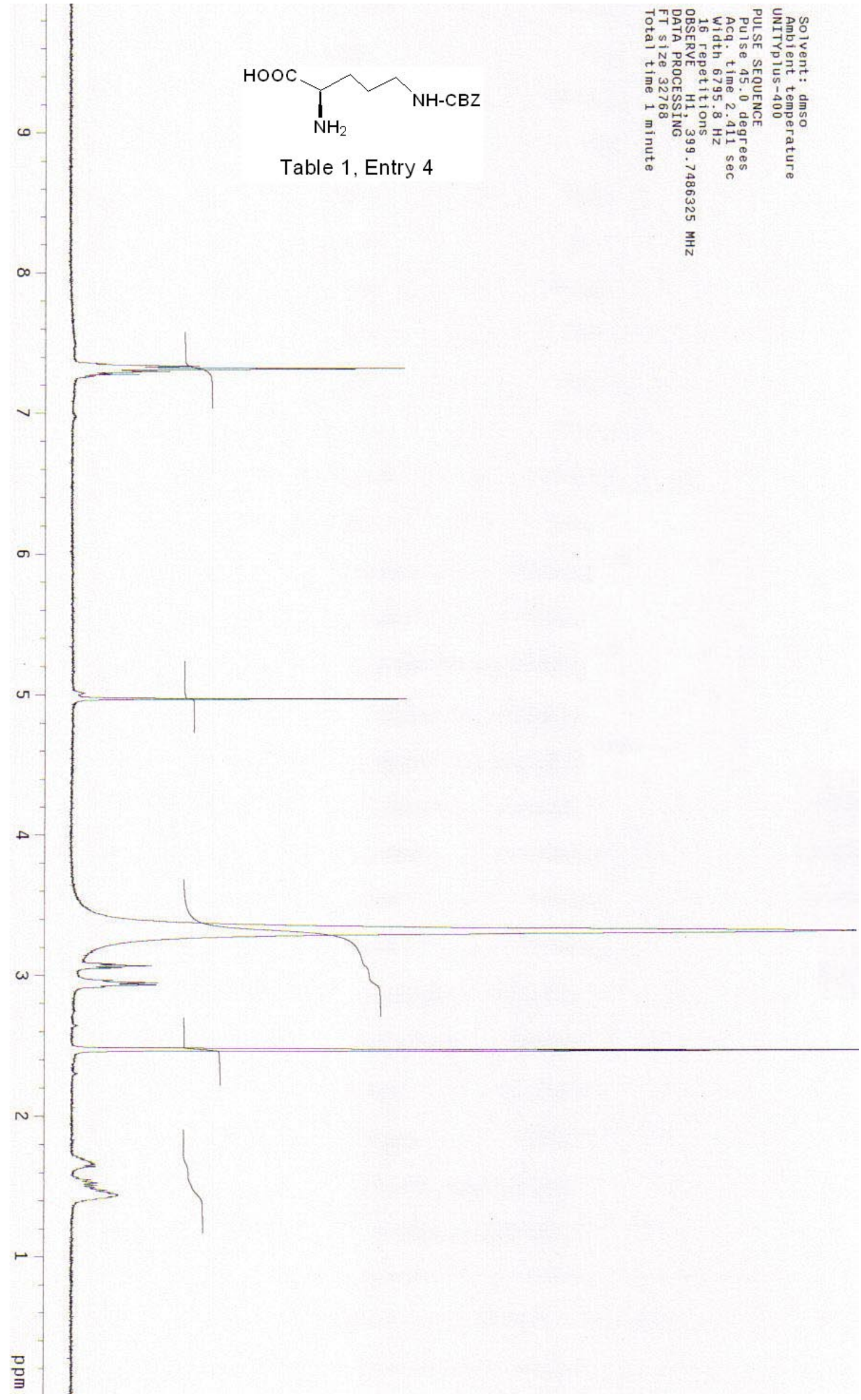




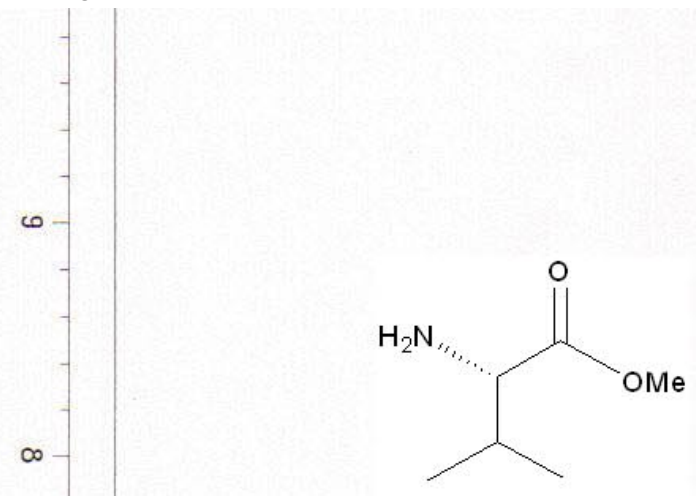

Table 1, Entry 5

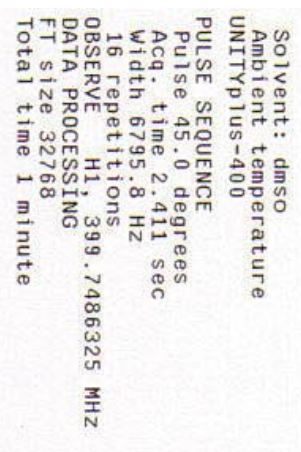


Supporting Information

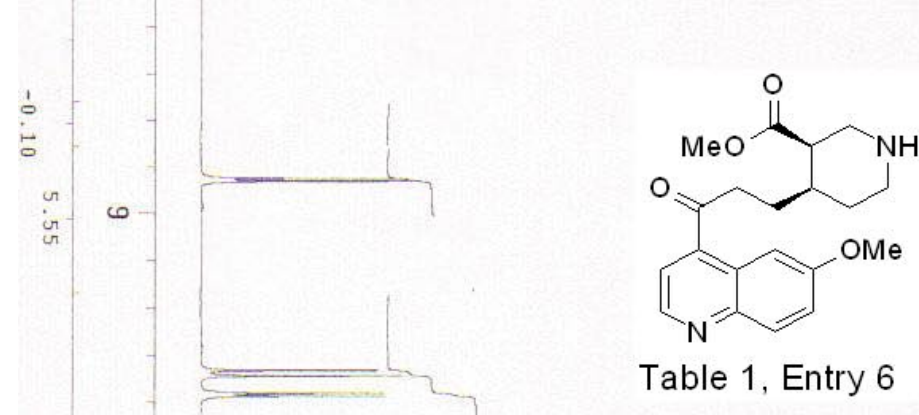

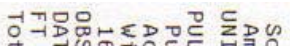
的㘳

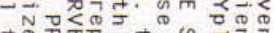
像 ติํำ

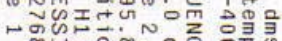

$\left.{ }^{\infty}\right)^{\infty}$

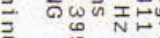

5

$\infty$

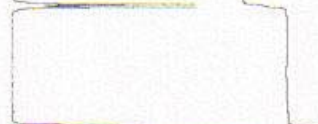

a

$\stackrel{\circ}{\omega}$

i

$\triangle$

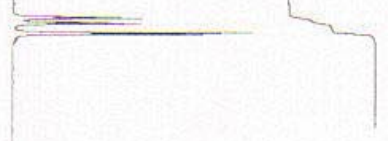

$\underset{\mathcal{N}}{\sim}$

조N 


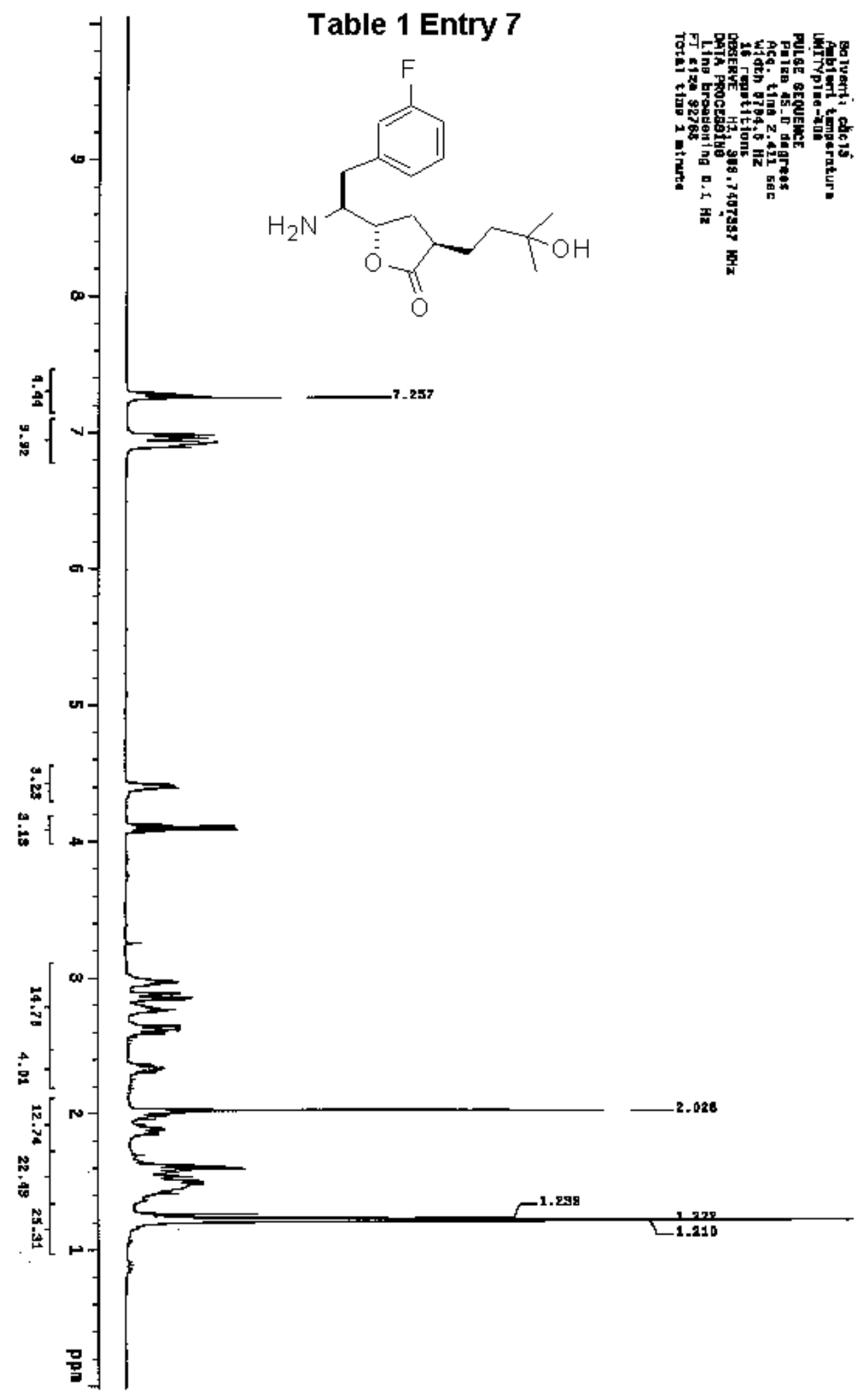



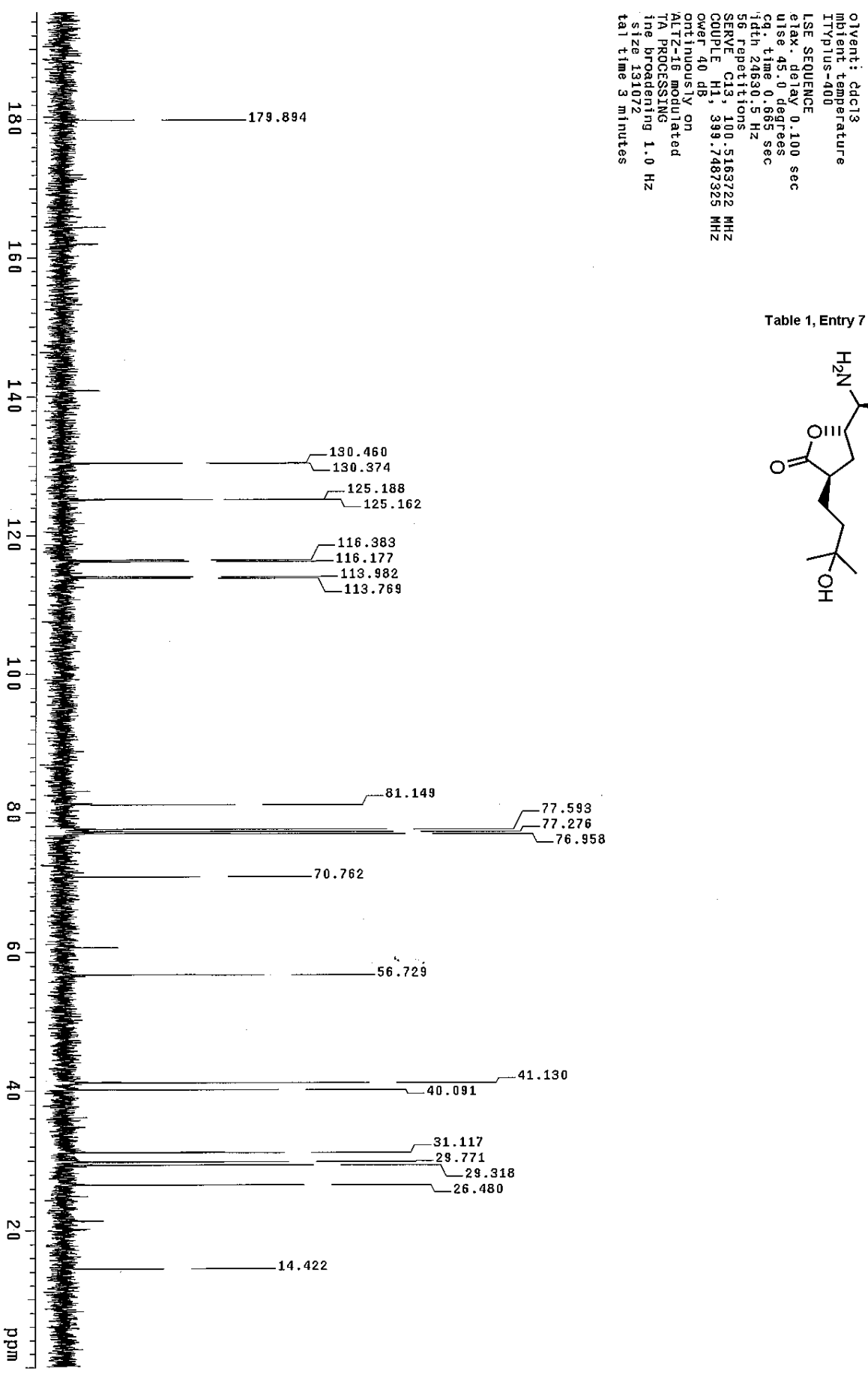

Table 1, Entry 7

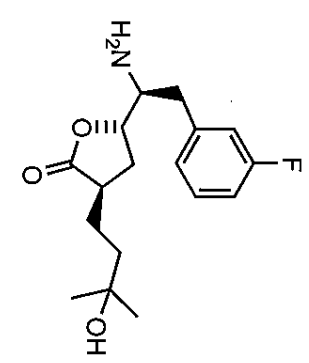




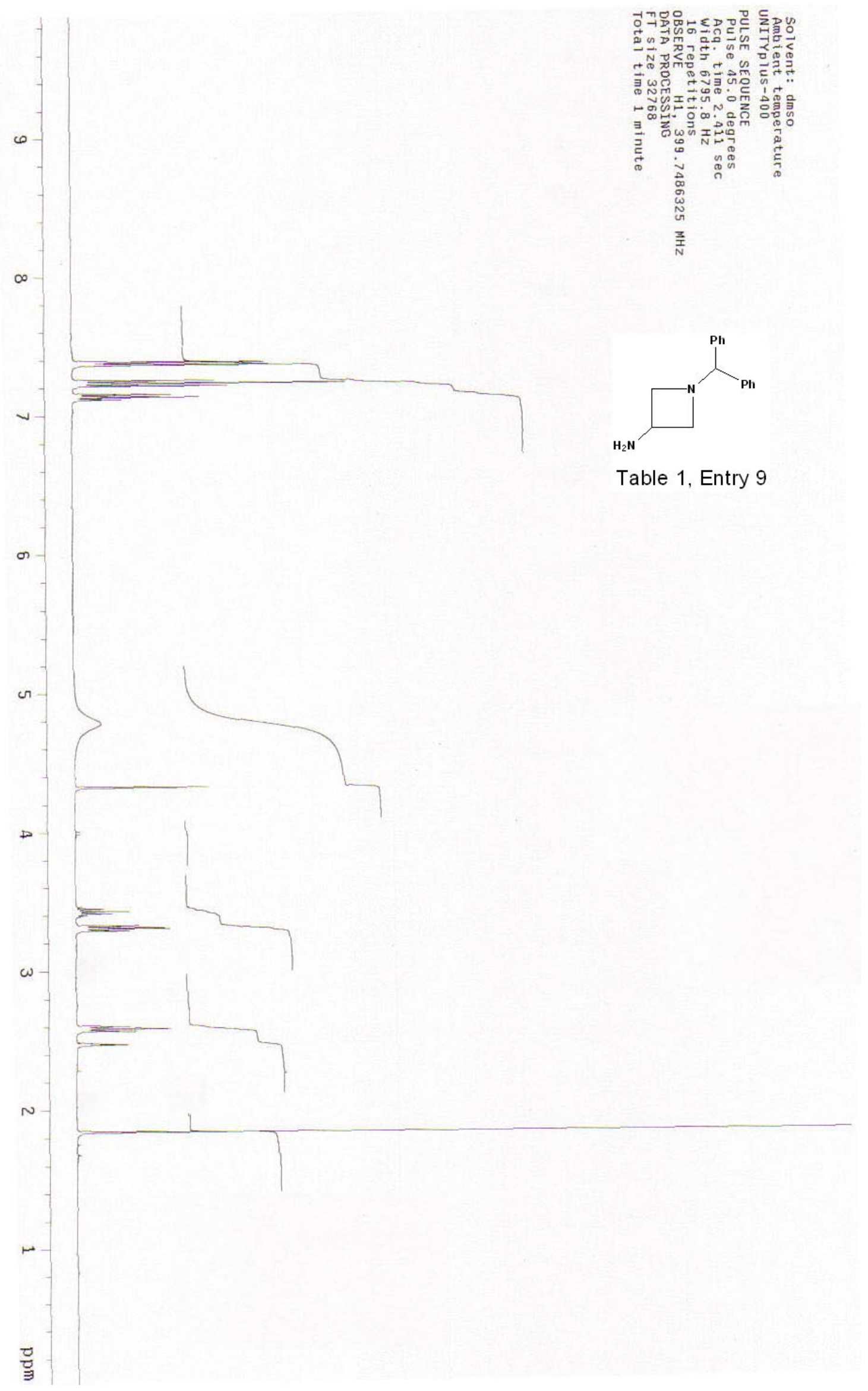




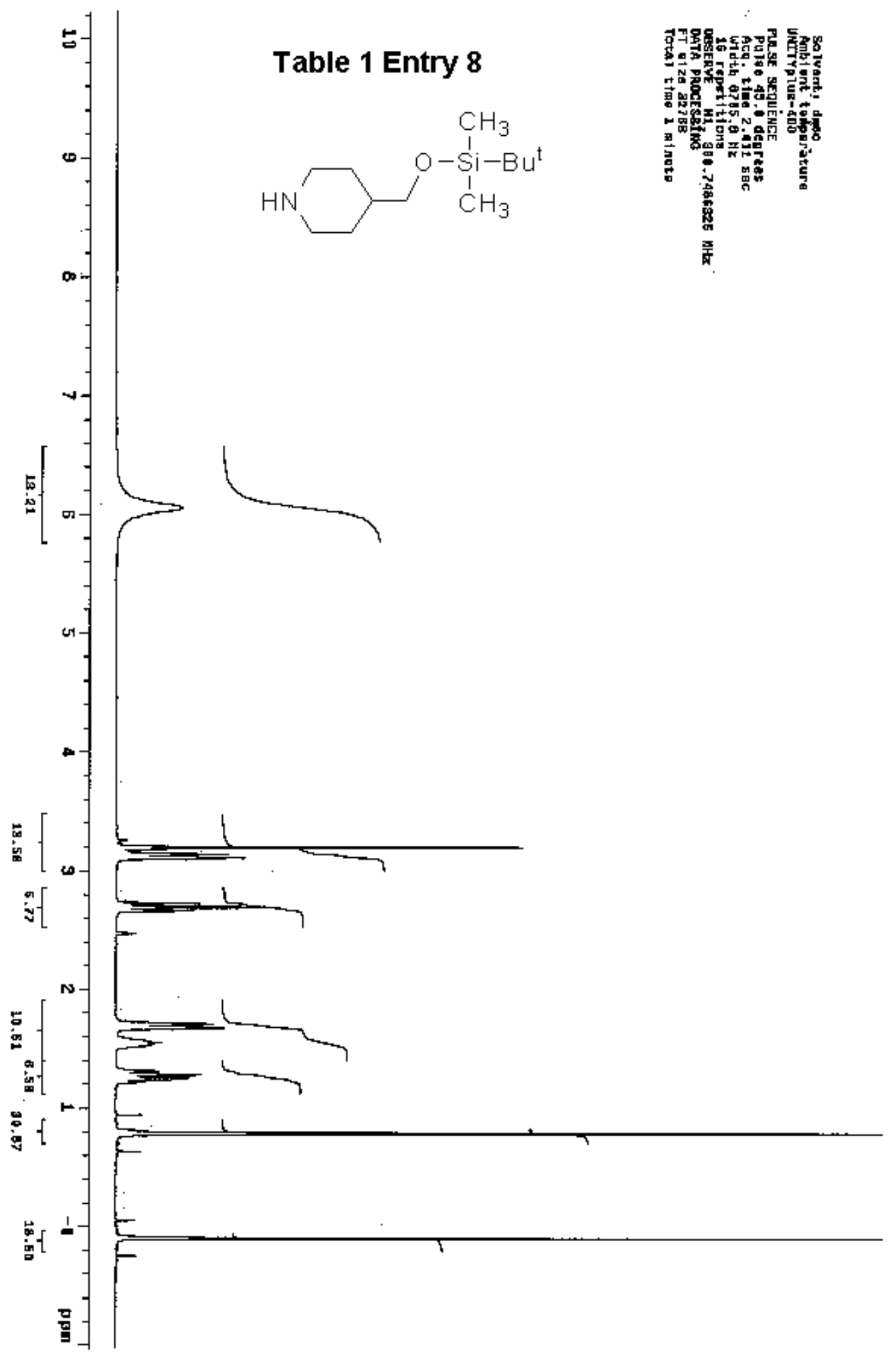




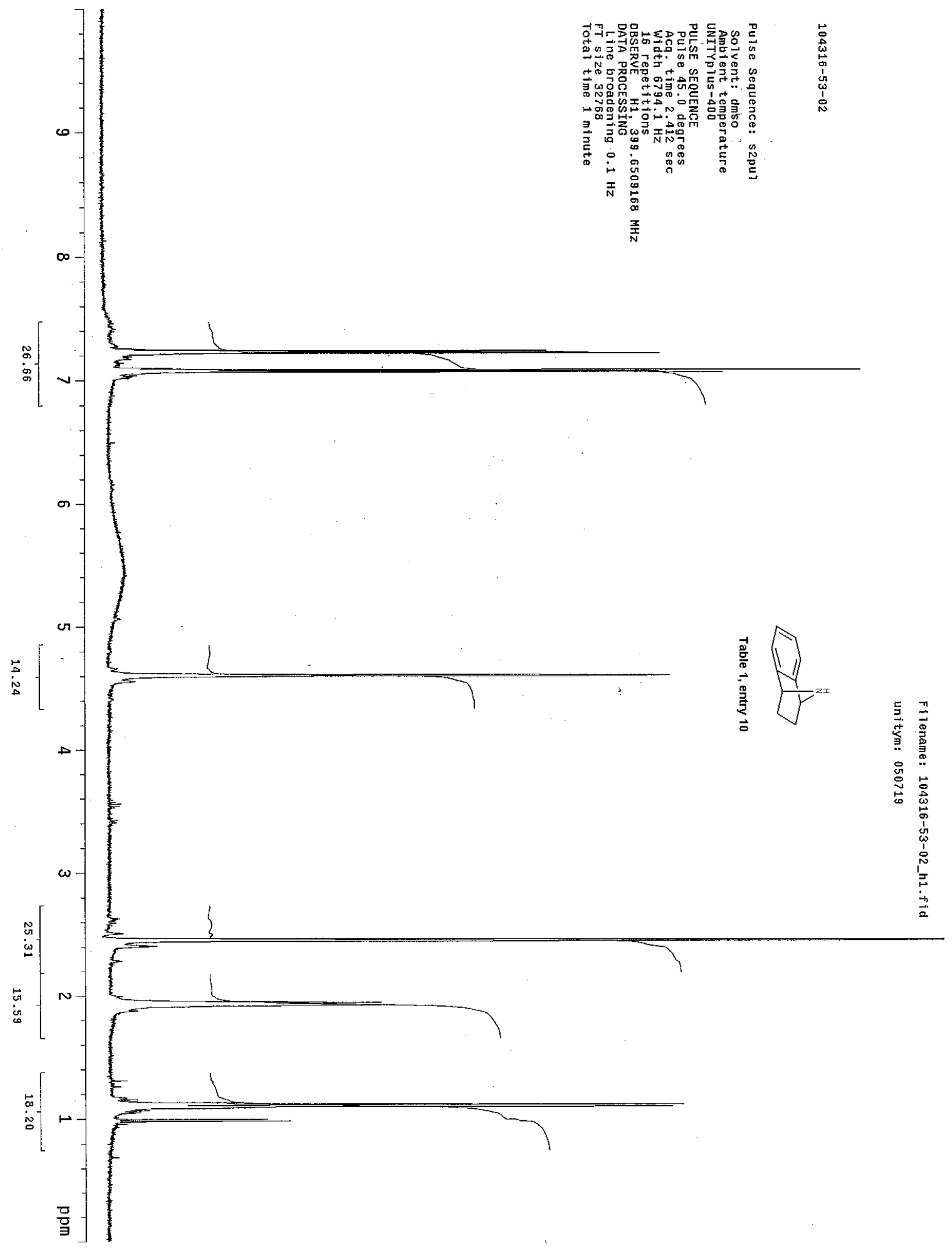


Characterization of Products in Table 2

\begin{tabular}{|c|c|c|}
\hline Entry & Product & Characterization \\
\hline 1 & Benzoic acid & $\begin{array}{l}{ }^{1} \mathrm{H} \mathrm{NMR}\left(\mathrm{CD}_{3} \mathrm{OD}\right) \delta 8.02(\mathrm{t}, 2 \mathrm{H}, \mathrm{J}=7.5), 7.58(\mathrm{~d}, 1 \mathrm{H}, \mathrm{J} \\
=7.5), 7.42(\mathrm{t}, 2 \mathrm{H}, \mathrm{J}=7.5), 4.93(1 \mathrm{H}, \mathrm{br} \mathrm{s})\end{array}$ \\
\hline 2 & N-Phthaloylglycine & ${ }^{1} \mathrm{H} \mathrm{NMR}\left(\mathrm{CD}_{3} \mathrm{OD}\right) \delta$ 7.88-7.78 $(\mathrm{m}, 4 \mathrm{H}), 4.40(\mathrm{~s}, 2 \mathrm{H})$ \\
\hline 3 & $\begin{array}{l}\text { N-(Carbobenzyloxy)-L- } \\
\text { Glutamic Acid }\end{array}$ & $\begin{array}{l}{ }^{1} \mathrm{H} \text { NMR }\left(\mathrm{CD}_{3} \mathrm{OD}\right) \delta 7.38-7.23(\mathrm{~m}, 5 \mathrm{H}), 5.03(\mathrm{~s}, 2 \mathrm{H}) \text {, } \\
4.96(\mathrm{br} \mathrm{s}, 1 \mathrm{H}), 4.22-4.18(\mathrm{~m}, 1 \mathrm{H}), 2.40(\mathrm{t}, 2 \mathrm{H}, \mathrm{J}=6.7 \\
\mathrm{Hz}), 2.22-2.04(\mathrm{~m}, 1 \mathrm{H}), 1.98-1.84(\mathrm{~m}, 1 \mathrm{H})\end{array}$ \\
\hline 4 & Benzyl Malonate & $\begin{array}{l}{ }^{1} \mathrm{H} \mathrm{NMR}\left(\mathrm{CD}_{3} \mathrm{OD}\right) \delta 7.38-7.24(\mathrm{~m}, 5 \mathrm{H}), 5.17(\mathrm{~s}, 2 \mathrm{H}) \\
3.40(\mathrm{~s}, 2 \mathrm{H})\end{array}$ \\
\hline 5 & $\begin{array}{l}\qquad \mathrm{N}-(9- \\
\text { Fluorenylmethoxycarbonyl)- } \\
\text { L-Aspartic Acid }\end{array}$ & $\begin{array}{l}{ }^{1} \mathrm{H} \text { NMR }\left(\mathrm{CD}_{3} \mathrm{OD}\right) \delta 7.80-7.24(\mathrm{~m}, 8 \mathrm{H}), 4.96(\mathrm{br} \mathrm{s} \\
2 \mathrm{H}), 4.60-4.19(\mathrm{~m}, 3 \mathrm{H}), 2.91-2.60(\mathrm{~m}, 2 \mathrm{H})\end{array}$ \\
\hline 6 & $\begin{array}{l}\text { N-(Benzyloxycarbonyl)-D- } \\
\text { Aspartic Acid }\end{array}$ & $\begin{array}{l}{ }^{1} \mathrm{H} \mathrm{NMR}\left(\mathrm{CD}_{3} \mathrm{OD}\right) \delta 7.38-7.21(\mathrm{~m}, 5 \mathrm{H}), 5.20-4.92 \\
(\mathrm{~m}, 3 \mathrm{H}), 4.68-4.65(\mathrm{~m}, 1 \mathrm{H}), 2.88-2.72(\mathrm{~m}, 2 \mathrm{H})\end{array}$ \\
\hline 7 & $\begin{array}{l}\text { 2'-O-Acetyl-11- } \mathrm{N} \text { - } \\
\text { carboxymethy-11,12- }\end{array}$ & See page $\mathbf{S} 28$ \\
\hline & cyclocarbamate ketolide ( 4 ) & \\
\hline
\end{tabular}




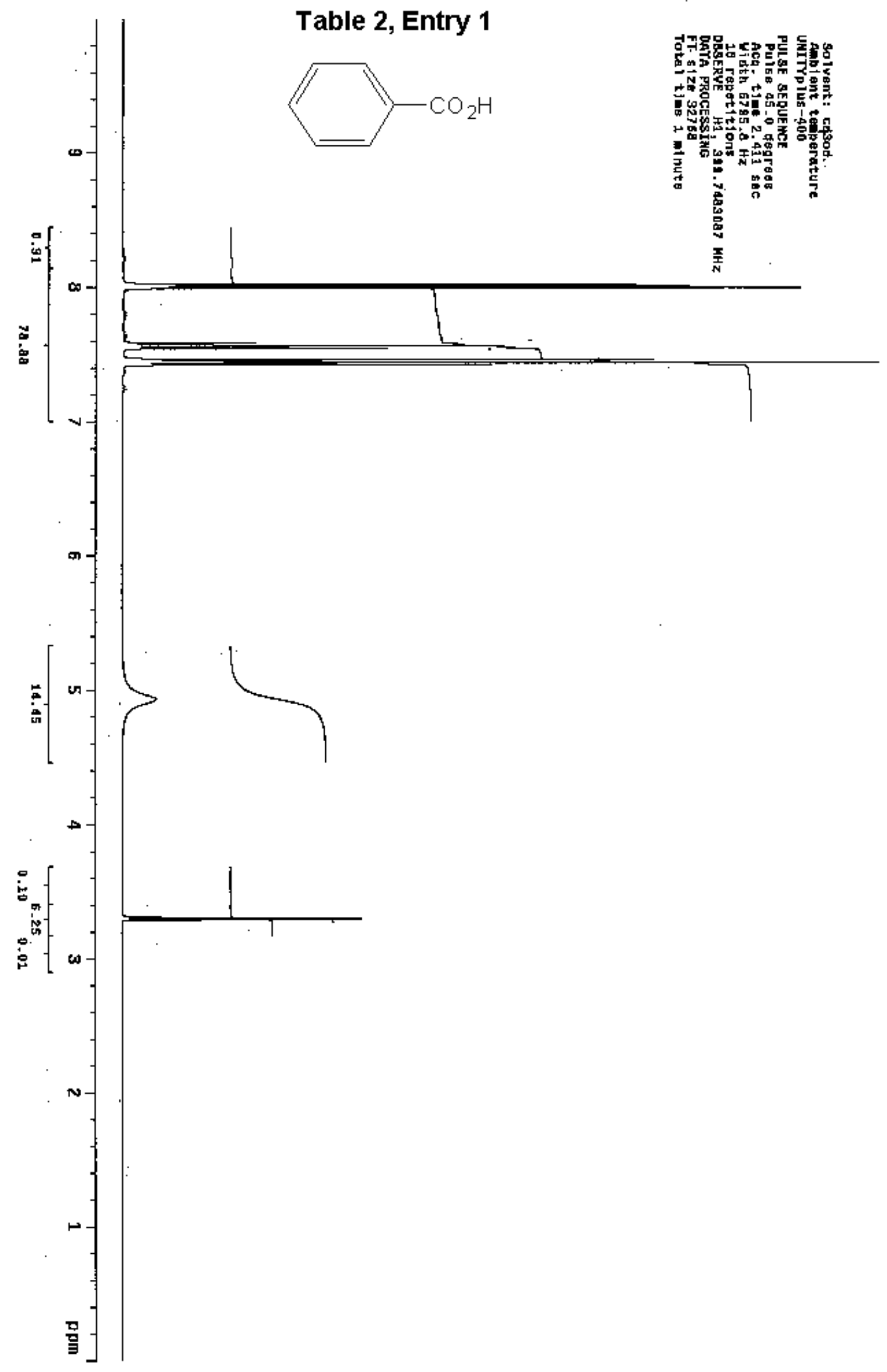


Table 2, Entry 2

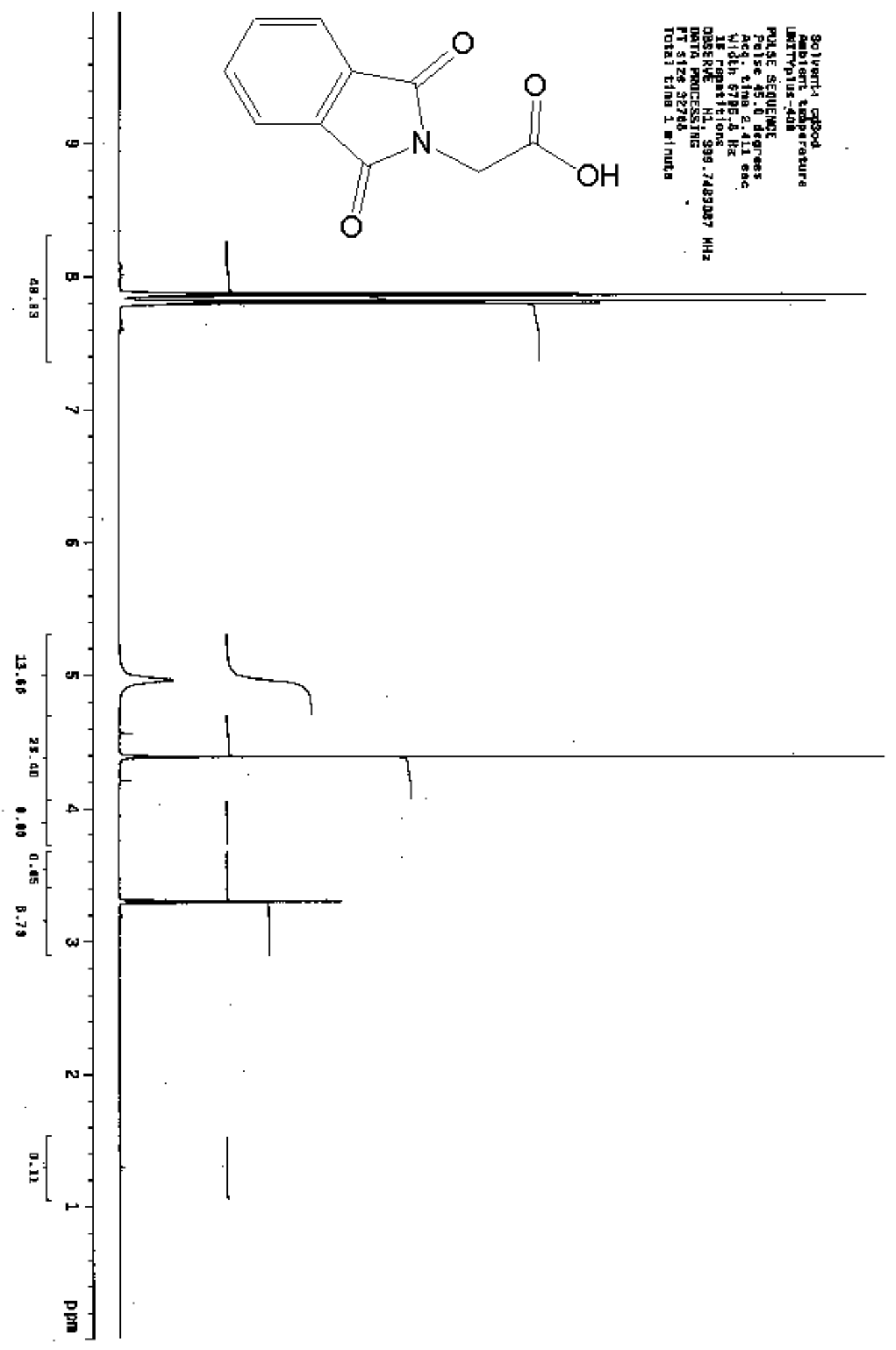




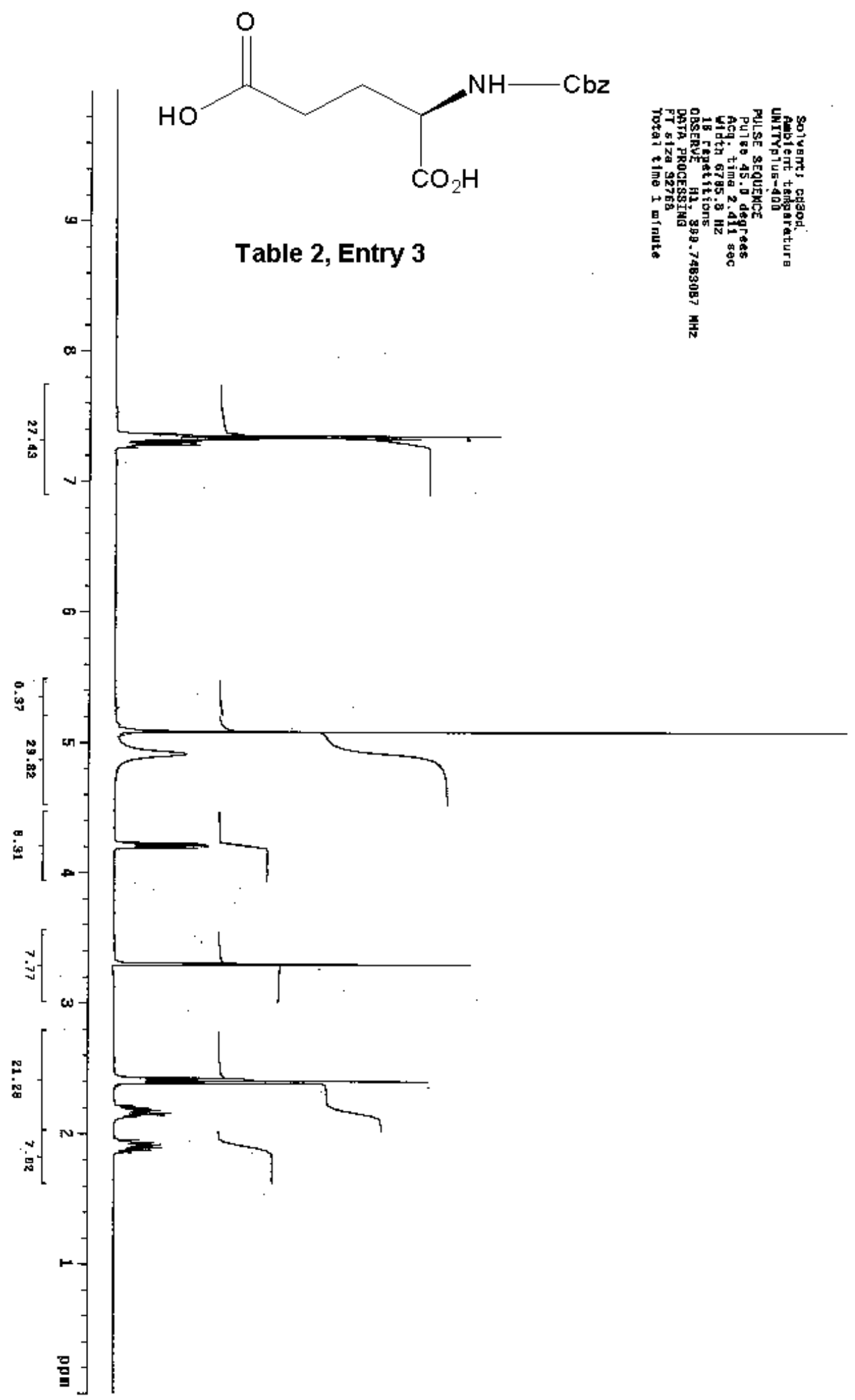




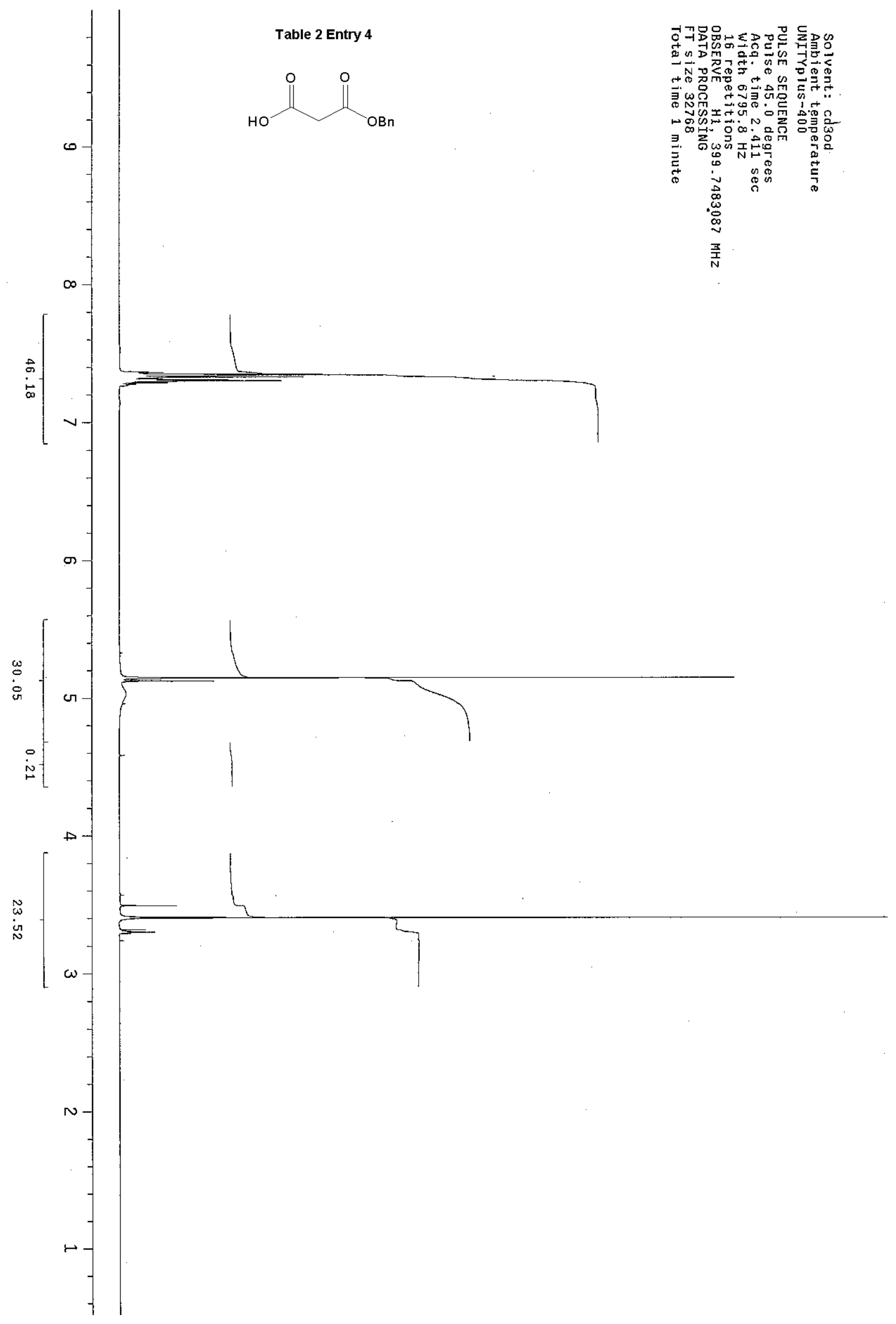




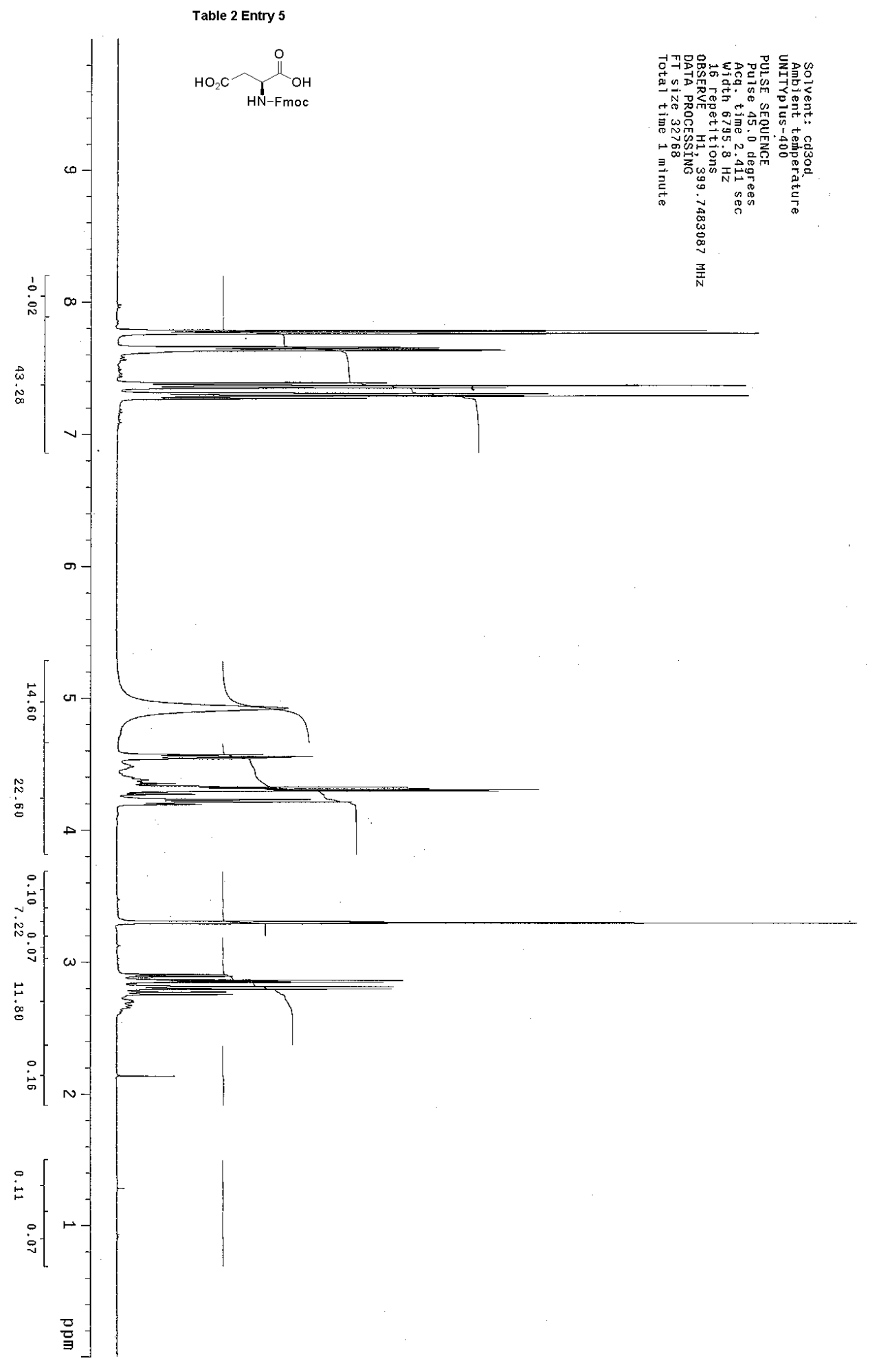




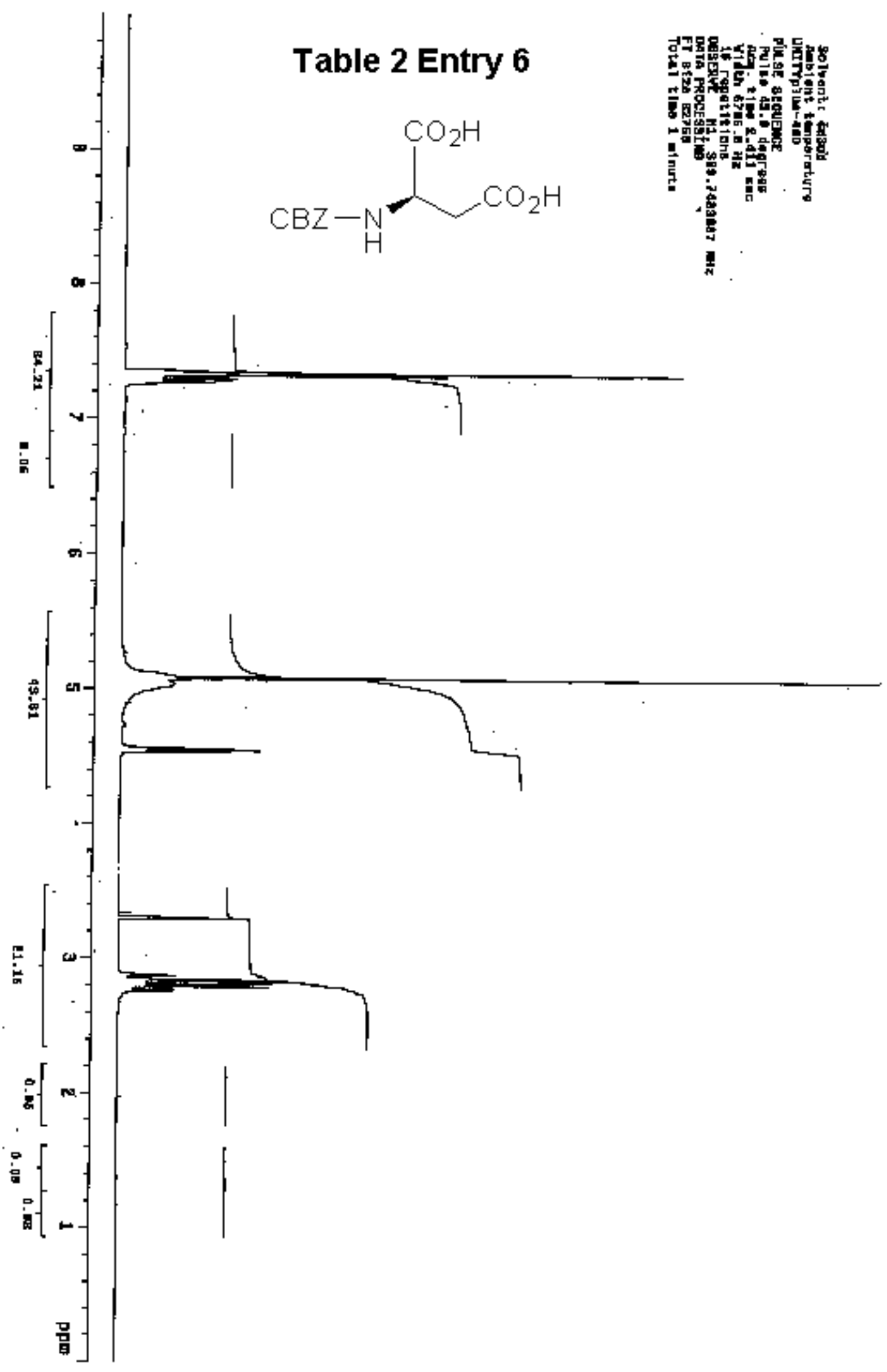




\section{Characterization of Products in Table 3}

\begin{tabular}{|c|c|c|}
\hline Entry & Product & Characterization \\
\hline \multirow{4}{*}{1} & $(2 S, 4 R)-1-$ & ${ }^{1} \mathrm{H}$ NMR $\left(\mathrm{DMSO}-\mathrm{d}_{6}\right) \delta 12.62(\mathrm{~s}, 1 \mathrm{H}), 7.38-7.23(\mathrm{~m}$, \\
\hline & (benzyloxycarbonyl)-4- & $5 \mathrm{H}), 5.19-4.98(\mathrm{~m}, 3 \mathrm{H}), 4.38-4.18(\mathrm{~m}, 2 \mathrm{H}), 3.47-$ \\
\hline & hydroxypyrrolidine-2- & $3.31(\mathrm{~m}, 2 \mathrm{H}), 2.20-2.04(\mathrm{~m}, 1 \mathrm{H}), 1.97-1.91(\mathrm{~m}, 1 \mathrm{H})$ \\
\hline & carboxylic acid & \\
\hline \multirow{3}{*}{2} & N hangulounurbonul I & ${ }^{1} \mathrm{H}$ NMR $\left(\right.$ DMSO-d $\left.{ }_{6}\right) \delta 7.39-7.22(\mathrm{~m}, 5 \mathrm{H}), 5.01(\mathrm{~s}, 2 \mathrm{H})$, \\
\hline & & $4.05-4.01(\mathrm{~m}, 1 \mathrm{H}), 3.62-3.59(\mathrm{~m}, 1 \mathrm{H}), 3.36(\mathrm{~s}, 1 \mathrm{H})$. \\
\hline & Serine & \\
\hline \multirow{3}{*}{3} & & ${ }^{1} \mathrm{H} \mathrm{NMR}\left(\mathrm{DMSO}-\mathrm{d}_{6}\right) \delta 7.39-7.22(\mathrm{~m}, 10 \mathrm{H}), 5.18-4.98$ \\
\hline & & $(\mathrm{m}, 5 \mathrm{H}), 4.80(\mathrm{~d}, 1 \mathrm{H}, \mathrm{J}=6.6 \mathrm{~Hz}), 4.12-4.03(\mathrm{~m}, 2 \mathrm{H})$ \\
\hline & Threonine-Benzyl Ester & $1.07(\mathrm{~d}, 3 \mathrm{H}, \mathrm{J}=6.6 \mathrm{~Hz})$ \\
\hline \multirow[b]{2}{*}{4} & & ${ }^{1} \mathrm{H}$ NMR $\left(\right.$ DMSO-d $\left._{6}\right) \delta 9.68(\mathrm{~s}, 1 \mathrm{H}), 7.29(\mathrm{~d}, 2 \mathrm{H}, \mathrm{J}=8.7$ \\
\hline & 4-bromophenol & $\mathrm{Hz}), 6.71(\mathrm{~d}, 2 \mathrm{H}, \mathrm{J}=8.7 \mathrm{~Hz})$ \\
\hline \multirow{3}{*}{5} & & ${ }^{1} \mathrm{H}$ NMR $\left(\right.$ DMSO-d $\left._{6}\right) \delta 10.24(\mathrm{~s}, 1 \mathrm{H}), 9.74(\mathrm{~s}, 1 \mathrm{H}), 7.39$ \\
\hline & N-benzyloxycarbonyl-4-(R)- & $(\mathrm{dd}, 1 \mathrm{H}, \mathrm{J}=8.3$ and $2.1 \mathrm{~Hz}), 7.35(\mathrm{~d}, 1 \mathrm{H}, \mathrm{J}=2.1 \mathrm{~Hz}), 6.9$ \\
\hline & Hydroxy-L-Proline & $(\mathrm{d}, 1 \mathrm{H}, \mathrm{J}=8.3 \mathrm{~Hz})$ \\
\hline
\end{tabular}


Supporting Information

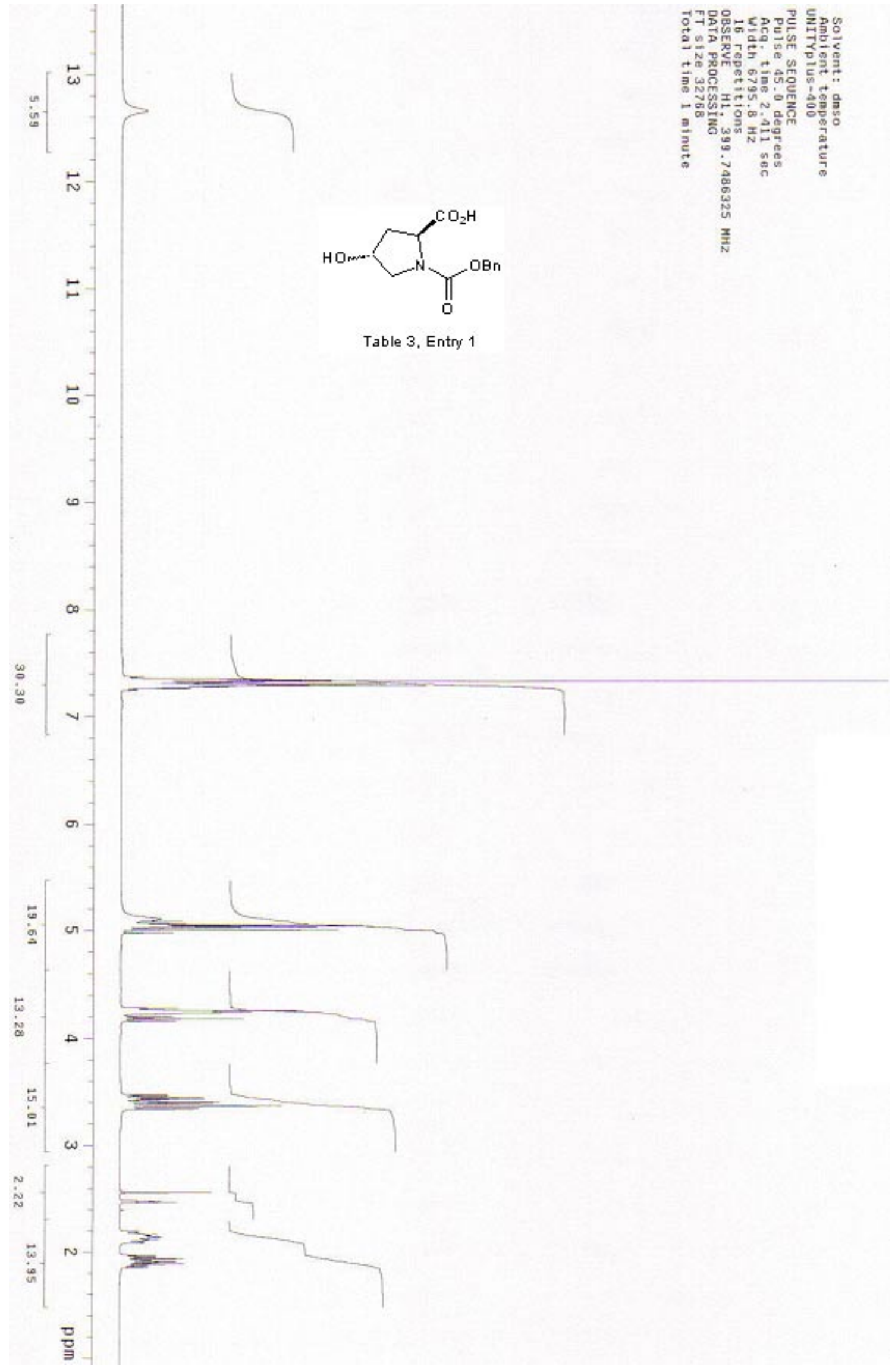




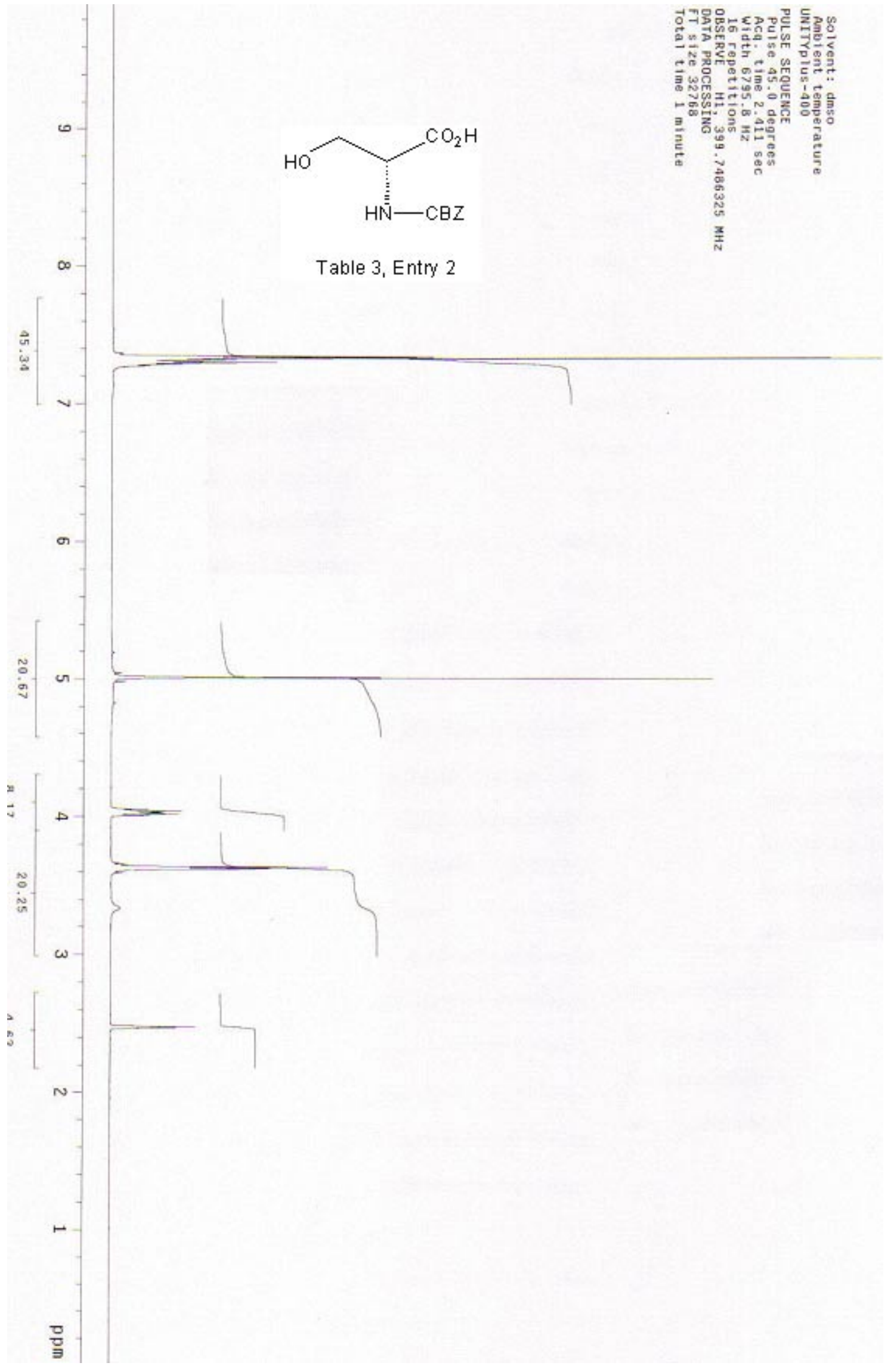


Supporting Information
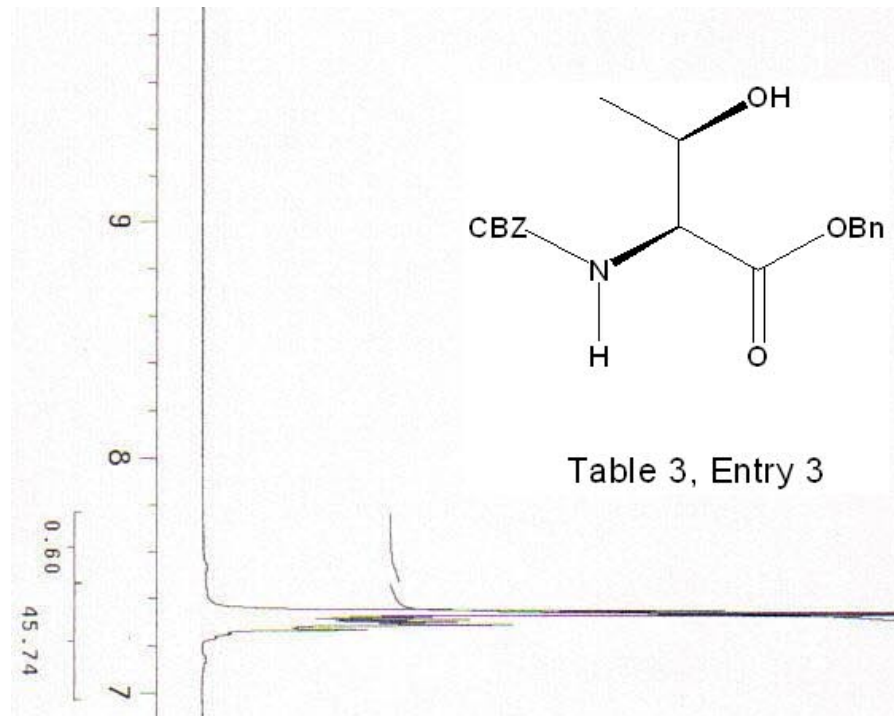

$\infty-$

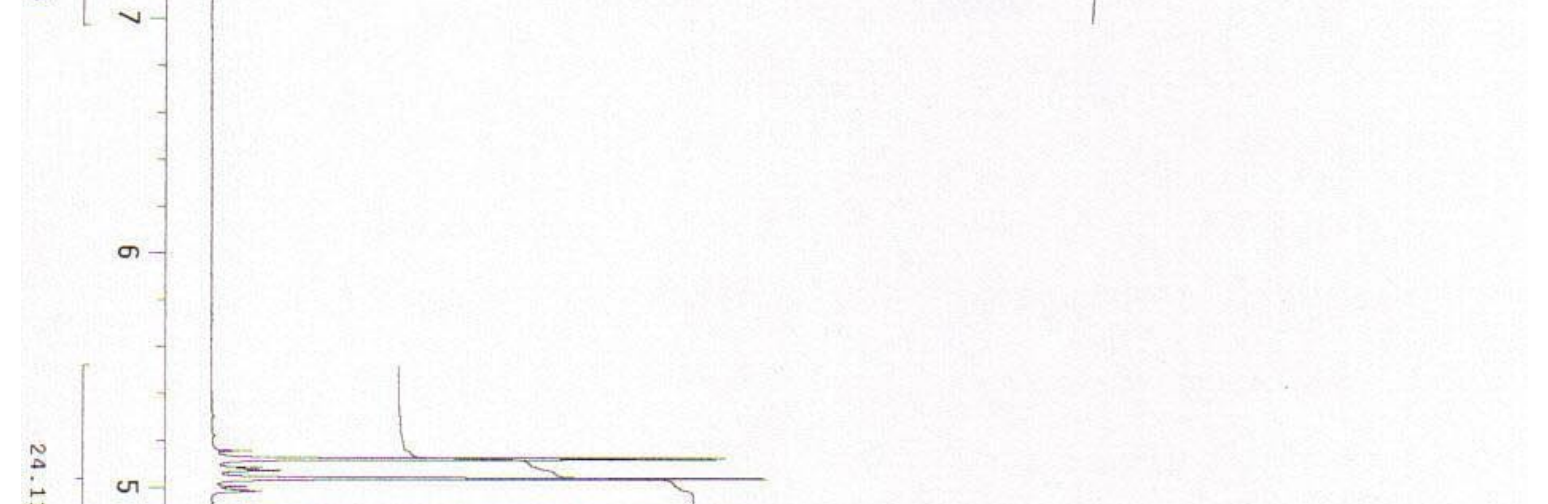

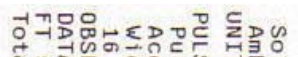

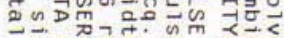

$\rightarrow$ N

जे $\omega$ مू

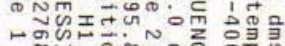

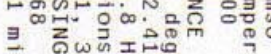

惢

조N

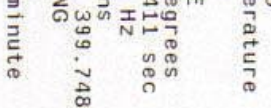

Table 3, Entry 3 


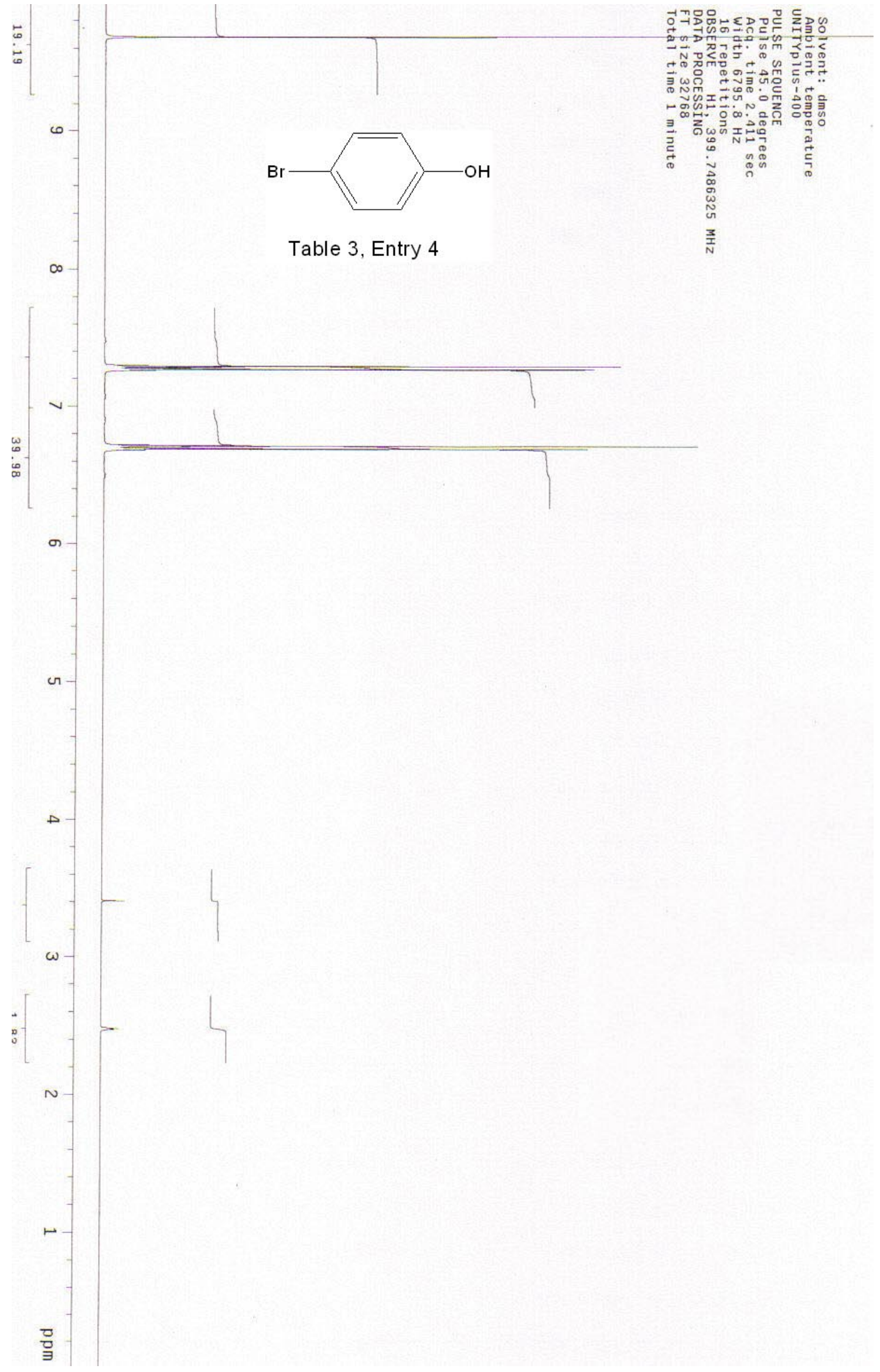




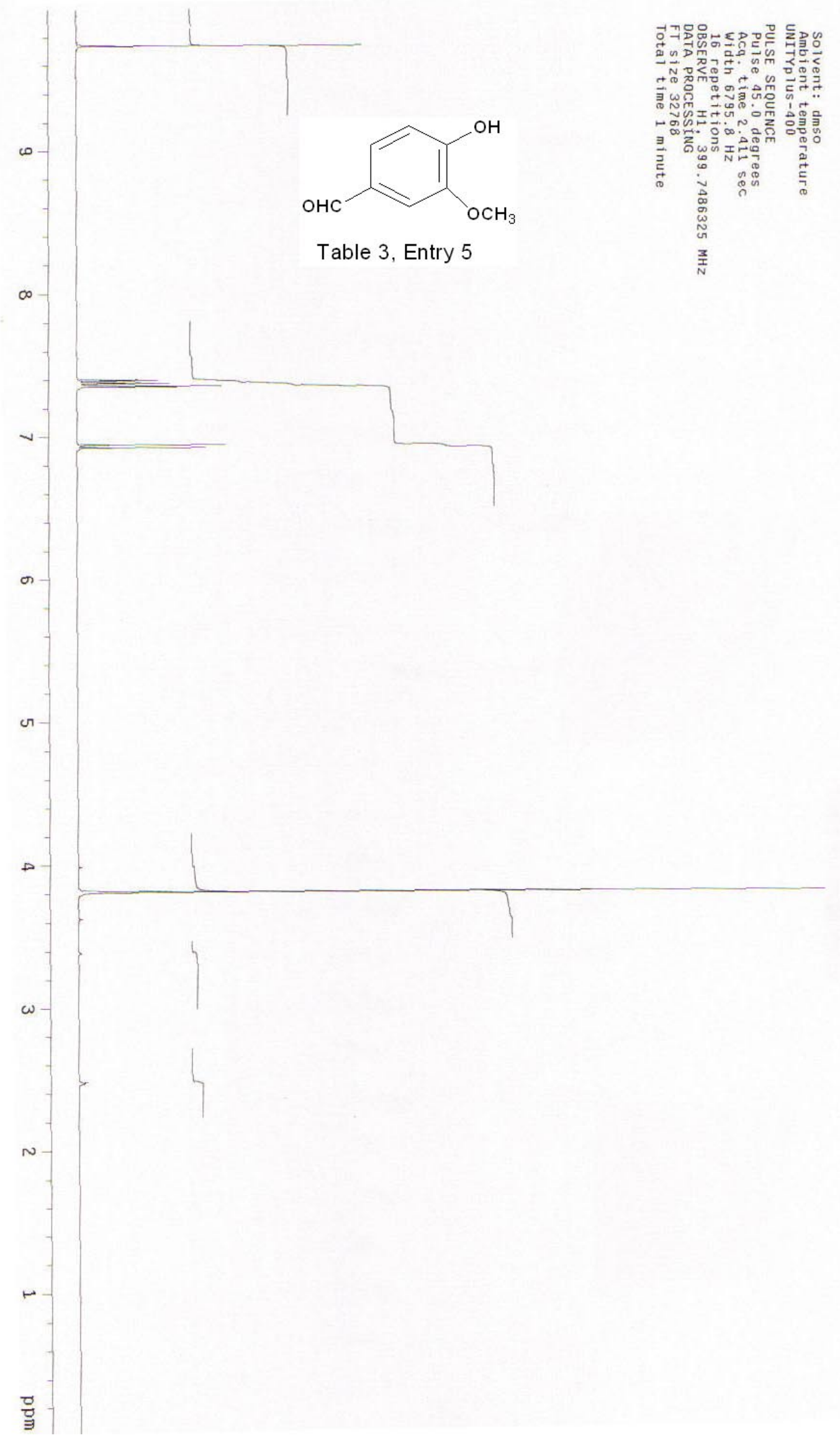




\title{
Characterization of Compound 4.
}

Both NMR and MS data are consistent with 4 below.

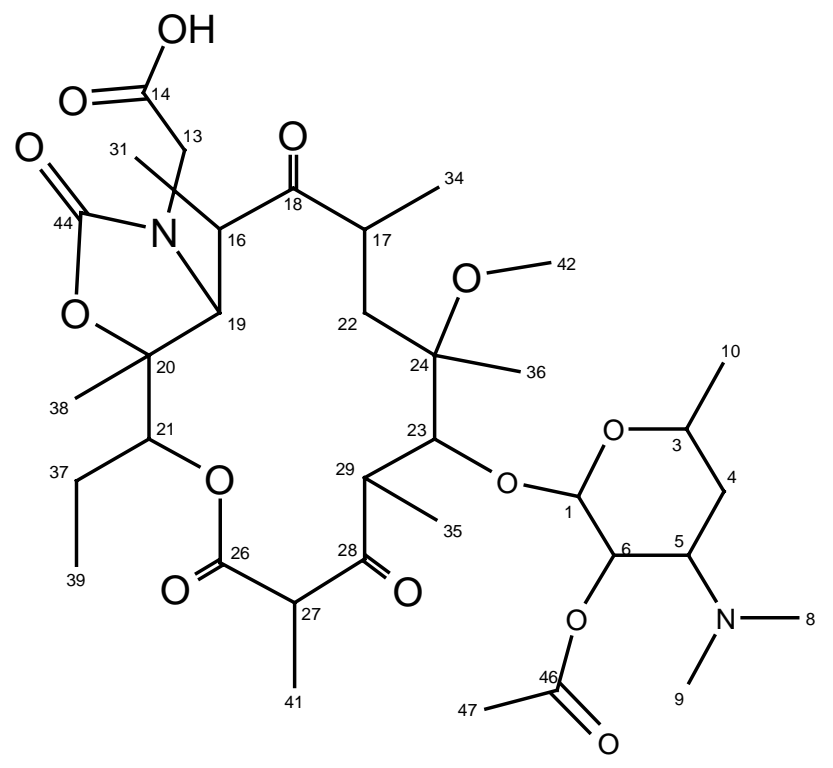

Compound 4

$$
\begin{aligned}
& \mathrm{MW}=712.8 \\
& \mathrm{C}_{35} \mathrm{H}_{56} \mathrm{~N}_{2} \mathrm{O}_{13}
\end{aligned}
$$

\section{$\underline{\text { LC-MS }}$}

\section{$\underline{\text { Sample Preparation }}$}

A sample of compound 4 was prepared at a concentration of $\sim 1 \mathrm{mg} / \mathrm{ml}$ in $50 \%$ acetonitrile/ $50 \%$ 20mM ammonium acetate $\mathrm{pH}: 3.1$.

\author{
Instrumentation
}


Nominal mass MS and MS-MS collision induced decomposition experiments were performed using the API quadrupole time of flight tandem mass spectrometer. For MS-MS studies, argon was used in the collision cell. Static and dynamic calibrations were performed in electrospray ionization mode with a solution of sodium iodide/cesium iodide. Interface and mass spectrometer tuning parameters were optimized on the drug substance by repeated flow injections.

The HPLC instrument used for these experiments was an modular system consisting of quaternary solvent pump, autosampler, UV/VIS detector, column oven and membrane solvent degasser. Mobile phase was mixed from individual components by the quaternary solvent pump and was composed of 50\% 20mM ammonium acetate and $50 \%$ acetonitrile. Column temperature was ambient and the flow rate was $1 \mathrm{ml} / \mathrm{min}$.

\section{$\underline{\text { NMR }}$}

\section{Sample Preparation}

Approximately $12 \mathrm{mg}$ of sample were dissolved in $0.8 \mathrm{~mL}$ of $99.9 \%$ chloroform- $d\left(\mathbf{C D C l}_{\mathbf{3}}\right)$ containing $0.05 \% \mathrm{w} / \mathrm{w}$ tetramethylsilane (TMS). The 1D proton and 1D carbon spectra were referenced using the TMS signal and set equal to $0.00 \mathrm{ppm}$.

\section{Instrumentation}

All 1D and 2D data were collected at $298 \mathrm{~K}$ using a $5 \mathrm{~mm}$ gradient broadband observe probe on a NMR spectrometer operating at $600 \mathrm{MHz}$.

\section{Experiments}

The following data were collected: 1D proton, 1D carbon, ${ }^{1} \mathrm{H}-{ }^{1} \mathrm{H}$ gradient DQFCOSY (Double Quantum-

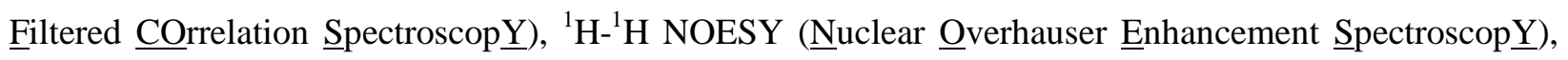




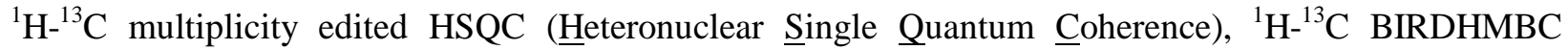

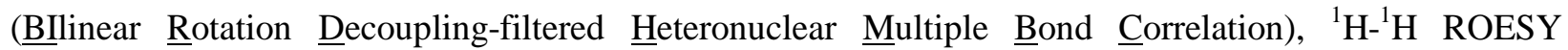

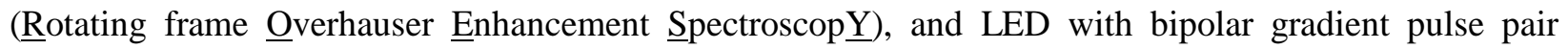
DOSY (Diffusion Ordered $\underline{\text { Spectroscop }} \underline{\text { ). }}$.

\section{RESULTS AND DISCUSSION}

\section{$\underline{\text { LC/MS }}$}

Figure 1 presents the mass spectrum for compound 4

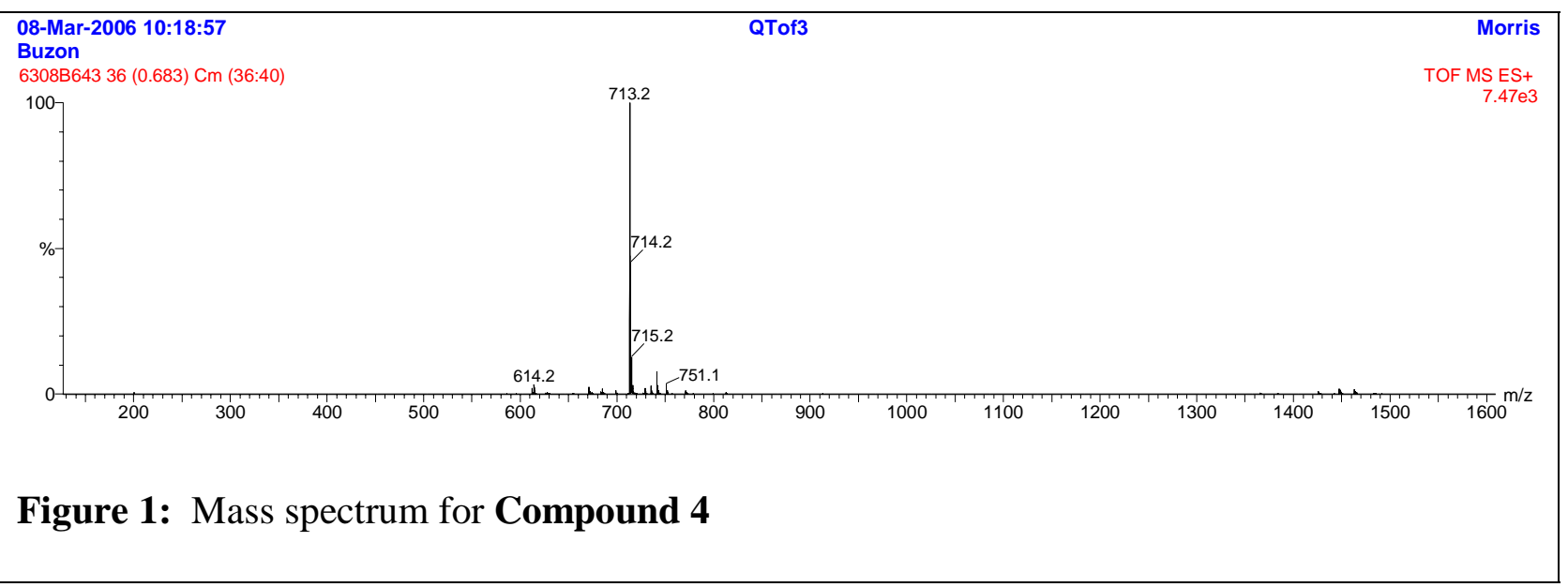

The spectrum is dominated by a species at $\mathrm{m} / \mathrm{z} 713$, consistent with a relative molecular mass (r.m.m.) of 712 Daltons. This is consistent with the expected structure for compound 4. Figure 2 presents the MS/MS collision induced dissociation (CID) spectrum of the $\mathrm{m} / \mathrm{z} 713$ species acquired at collision cell voltages of 20 and $40 \mathrm{~V}$. 


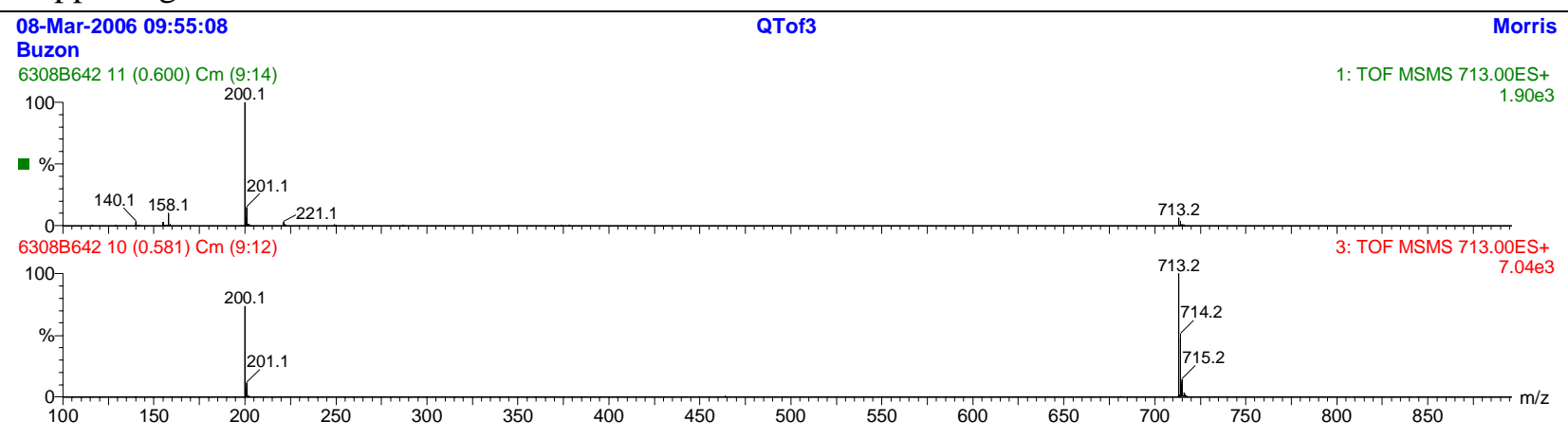

Figure 2: MS/MS CID spectrum for compound 4 acquired at 20V (bottom panel) and 40V (top panel) $)^{1}$

The spectra contain a main fragment at m/z 200 likely due to cleavage between the oxygen and the sugar ring system. A small fragment at $\mathrm{m} / \mathrm{z} 158$ is likely due to cleavage between the sugar ring oxygen and the macrolide ring followed by loss of the acetyl group.

\section{NMR}

The 1D proton spectrum shows the expected chemical shifts, multiplicities and integrations that are consistent with structure 1 and the main component in the sample. The 1D carbon spectrum is consistent with structure 1 based upon chemical shift. The 2D spectra show the expected vicinal and geminal ${ }^{1} \mathrm{H}_{-}{ }^{13} \mathrm{C}$ and ${ }^{1} \mathrm{H}_{-}{ }^{1} \mathrm{H}$ correlations. Key homonuclear and heteronuclear correlations are indicated in figure 3. Proton and carbon assignments are tabulated in table 1.

The stereochemistry of this compound was not explicitly evaluated.

Additional components at approximately equimolar amounts as the main component were detected in this sample. In the $1 \mathrm{D}$ proton spectrum three multiplets at $8.63,7.71$ and $7.31 \mathrm{ppm}$ do not show any correlations to resonances any other components as determined by multiple NMR data. In the HMBC spectrum the proton resonance at $8.63 \mathrm{ppm}$ shows correlations to carbons at 
123.9 and $136.4 \mathrm{ppm}$, which correspond to the proton resonances at 7.31 and $7.71 \mathrm{ppm}$,

respectively. The protons at 7.31 and $7.71 \mathrm{ppm}$ are further coupled to a carbon at $149.3 \mathrm{ppm}$ which correspond to the proton multiplet at $8.63 \mathrm{ppm}$. Heteronuclear $\mathrm{H}, \mathrm{C}$-correlations were determined through analysis of the mulitiplicity edited HSQC spectrum. In addition, these protons are homonuclear coupled in the COSY data.

Additional resonances detected in the 1D proton spectrum at 1.20, 2.76 and $3.01 \mathrm{ppm}$ also do not show any correlations to resonances any component as determined by the analysis of multiple NMR data.

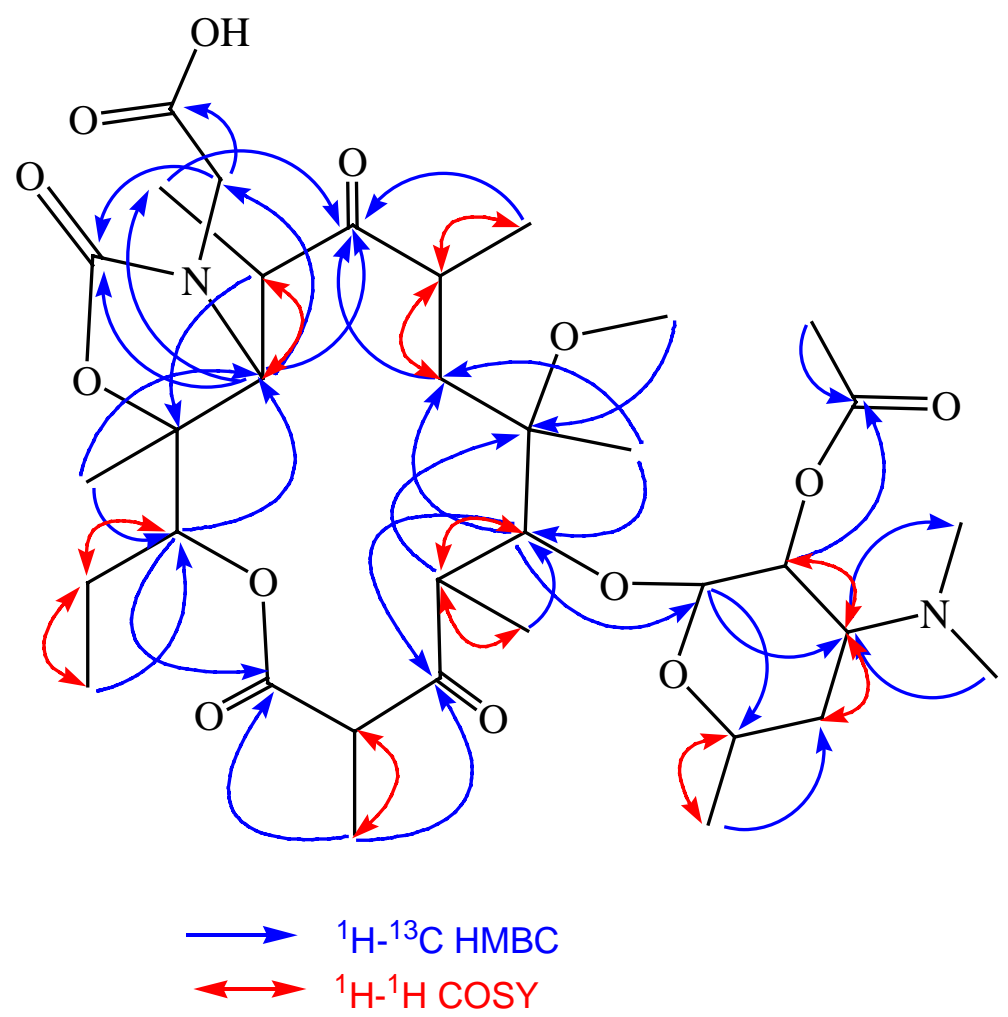

Figure 3. Structure 1 with arrows indicating key $2 \mathrm{D}$ long-range $\left({ }^{\mathrm{n}} J_{\mathrm{CH}}, \mathrm{n}=2,3\right)$ heteronuclear couplings (shown in red) and geminal homonuclear couplings (shown in blue). 


\begin{tabular}{|c|c|c|c|c|}
\hline CARBON \# & $\begin{array}{c}\text { CARBON } \\
\text { (PPM) }\end{array}$ & $\begin{array}{c}\text { H's } \\
\text { ATTACHED }\end{array}$ & $\begin{array}{c}\text { PROTON } \\
\text { (PPM) }\end{array}$ & $\begin{array}{c}\text { PROTON } \\
\text { MULTIPLICITY }\end{array}$ \\
\hline 1 & 100.9 & 1 & 4.39 & $\mathrm{~d}$ \\
\hline 3 & 68.8 & 1 & 3.56 & $\mathrm{~m}$ \\
\hline 4 & 30.8 & 2 & $\begin{array}{l}1.37 \\
1.84\end{array}$ & $\begin{array}{l}\mathrm{m} \\
\mathrm{m}\end{array}$ \\
\hline 5 & 62.5 & 1 & 3.01 & $\mathrm{~m}$ \\
\hline 6 & 70.9 & 1 & 4.80 & $\mathrm{t}$ \\
\hline 8 & 39.7 & 3 & 2.33 & $\mathrm{~s}$ \\
\hline 9 & 39.7 & 3 & 2.33 & $\mathrm{~s}$ \\
\hline 10 & 20.9 & 3 & 1.26 & $\mathrm{~d}$ \\
\hline 13 & 45.7 & 2 & $\begin{array}{l}4.25 \\
4.53\end{array}$ & $\begin{array}{l}\mathrm{d} \\
\mathrm{d}\end{array}$ \\
\hline 14 & 173.1 & 0 & & \\
\hline 16 & 39.1 & 1 & 3.01 & $\mathrm{~m}$ \\
\hline 17 & 44.9 & 1 & 2.57 & $\mathrm{~m}$ \\
\hline 18 & 216.4 & 0 & & \\
\hline 19 & 61.8 & 1 & 3.69 & $\mathrm{~s}$ \\
\hline 20 & 82.6 & 0 & & \\
\hline 21 & 78.2 & 1 & 5.71 & $\mathrm{~d}$ \\
\hline 22 & 39.4 & 2 & $\begin{array}{l}1.53 \\
1.64\end{array}$ & $\mathrm{~m}$ \\
\hline
\end{tabular}




\begin{tabular}{|c|c|c|c|c|}
\hline 23 & 77.6 & 1 & 4.16 & d \\
\hline 24 & 77.9 & 0 & & \\
\hline 26 & 168.7 & 0 & & \\
\hline 27 & 51.4 & 1 & 3.81 & $q$ \\
\hline 28 & 204.6 & 0 & & \\
\hline 29 & 47.0 & 1 & 3.01 & $\mathrm{~m}$ \\
\hline 31 & 14.5 & 3 & 1.05 & $\mathrm{~d}$ \\
\hline 34 & 18.2 & 3 & 1.16 & $\mathrm{~d}$ \\
\hline 35 & 14.1 & 3 & 1.13 & $\mathrm{~d}$ \\
\hline 36 & 19.3 & 3 & 1.26 & $\mathrm{~S}$ \\
\hline 37 & 22.8 & 2 & $\begin{array}{l}1.53 \\
2.00\end{array}$ & $\begin{array}{l}\mathrm{m} \\
\mathrm{m}\end{array}$ \\
\hline 38 & 14.8 & 3 & 1.49 & $\mathrm{~S}$ \\
\hline 39 & 10.8 & 3 & 0.89 & $\mathrm{t}$ \\
\hline 41 & 15.8 & 3 & 1.35 & $\mathrm{~d}$ \\
\hline 42 & 49.1 & 3 & 2.53 & $\mathrm{~S}$ \\
\hline 44 & 157.6 & 0 & & \\
\hline 46 & 170.0 & 0 & & \\
\hline 47 & 21.4 & 3 & 2.09 & $\mathrm{~S}$ \\
\hline
\end{tabular}

$\mathrm{s}=$ singlet, $\mathrm{d}=$ doublet, $\mathrm{dd}=$ doublet of doublets, $\mathrm{dt}=$ doublet of triplets, $\mathrm{dq}=$ doublet of quartets, $\mathrm{t}=$ triplet, $\mathrm{t} \mathrm{t}=$ triplet of triplets, $\mathrm{q}=$ quartet, $\mathrm{m}=$ multiplet

Table 1. Table of carbon assignments, number of protons on each carbon, proton assignments and multiplicities. 


\section{CONCLUSIONS}

The 1D proton spectrum shows the expected chemical shifts, multiplicities and integrations that are consistent with structure 1 . The $1 \mathrm{D}{ }^{13} \mathrm{C}$ spectrum is consistent with structure 1 based upon chemical shift. The 2D spectra show the expected vicinal and geminal ${ }^{1} \mathrm{H}-{ }^{13} \mathrm{C}$ and ${ }^{1} \mathrm{H}-{ }^{1} \mathrm{H}$ correlations. Therefore, the spectra are consistent with compound 4.

The MS and MS/MS spectra are consistent with compound 4. 


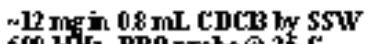 $600 \mathrm{ML}, \mathrm{BB} 0$ probe $@ 25 \mathrm{c}$}

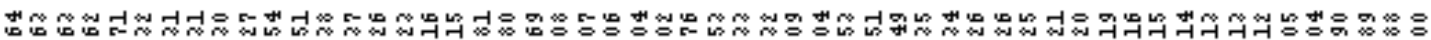

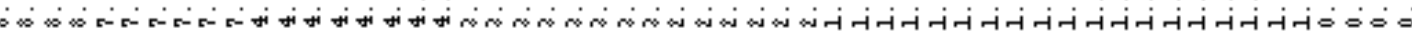
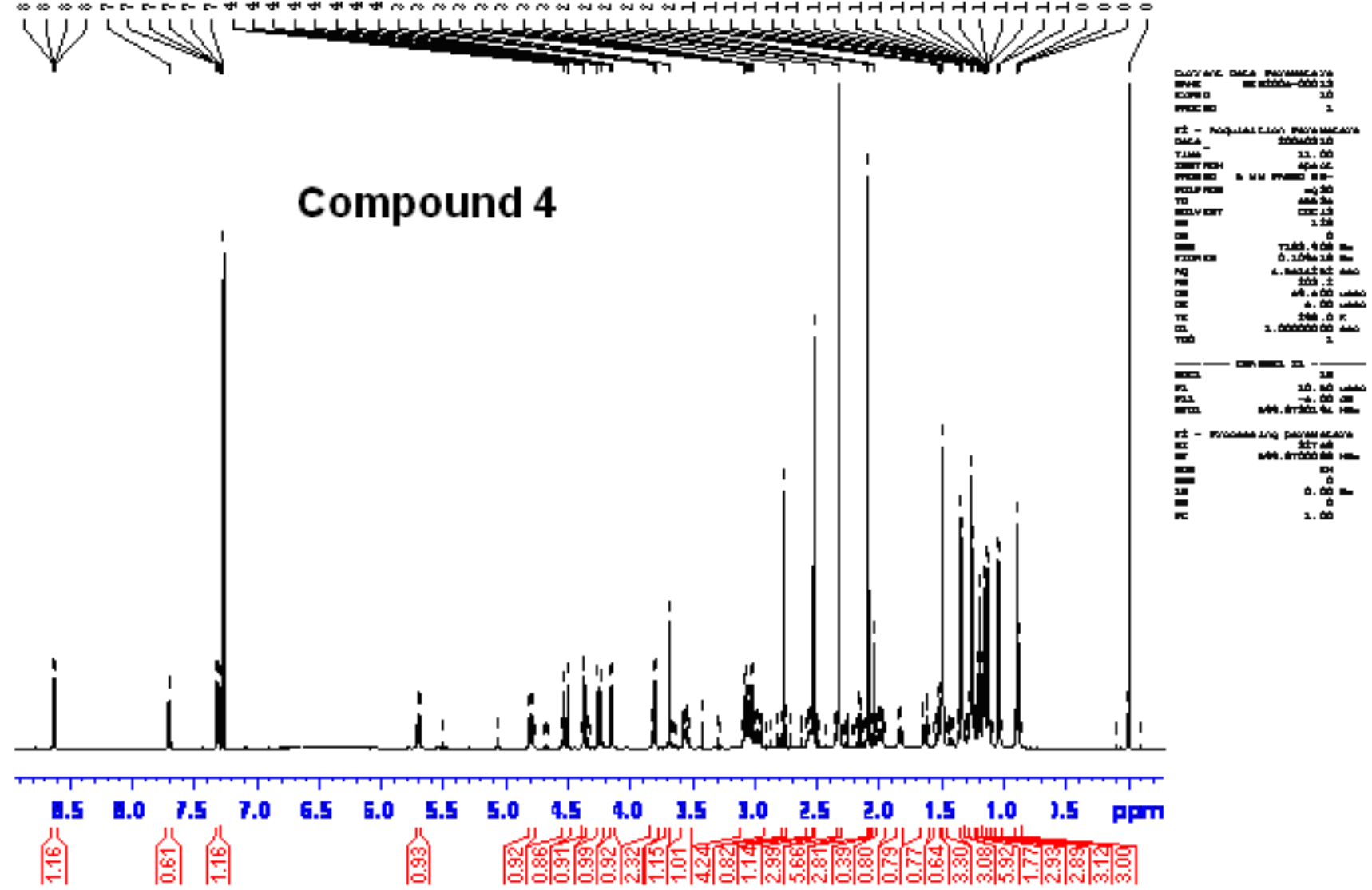


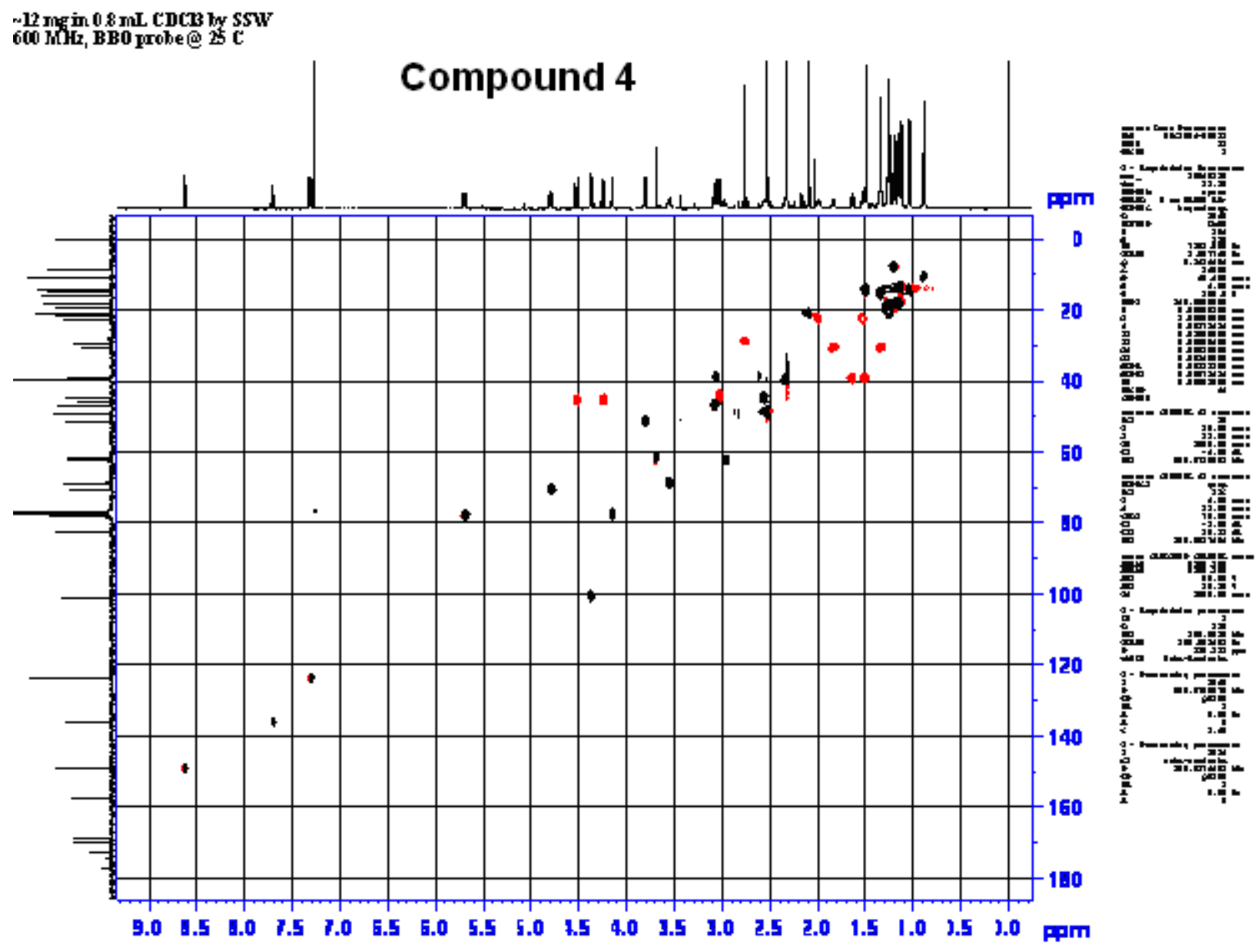




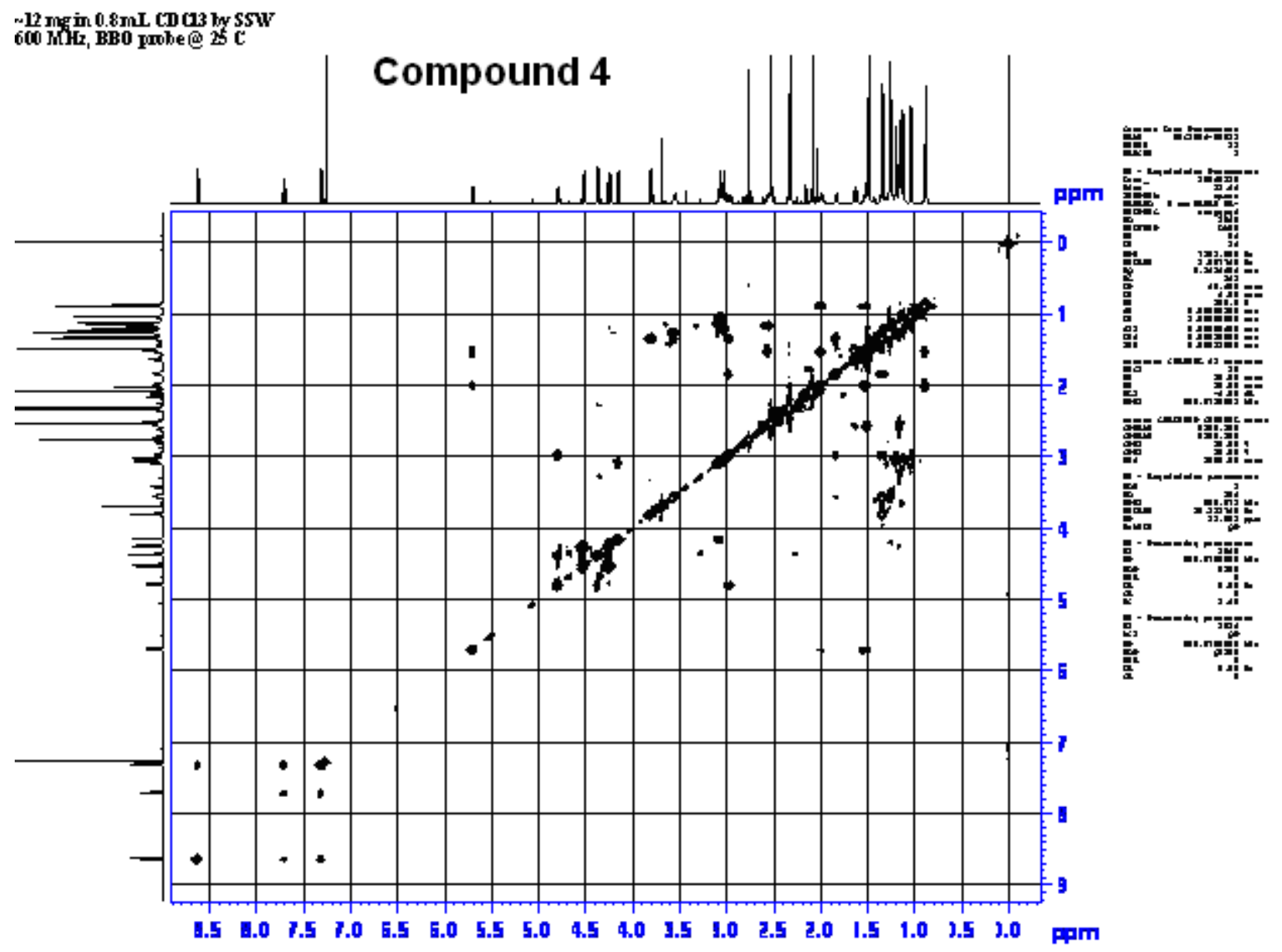




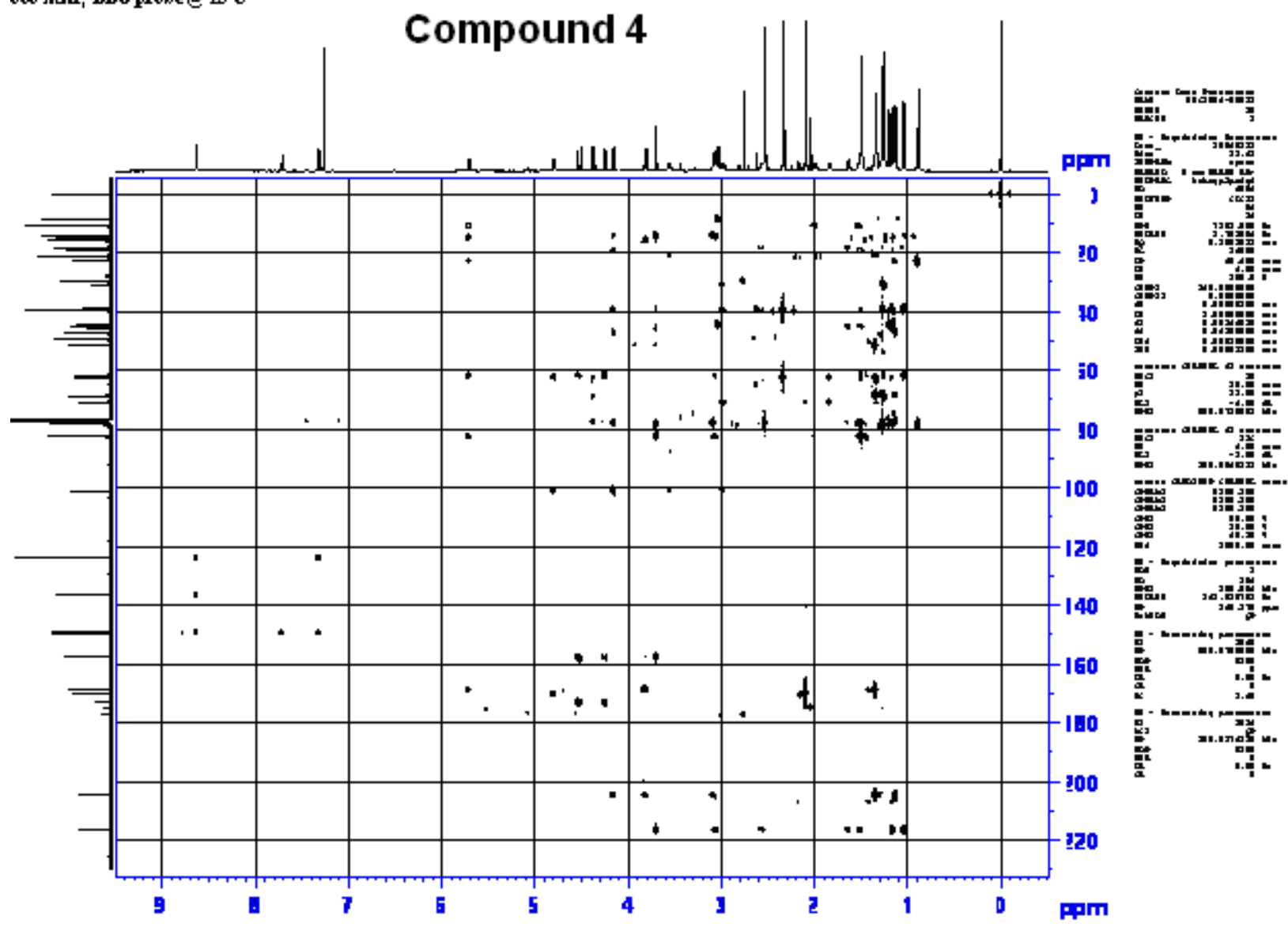




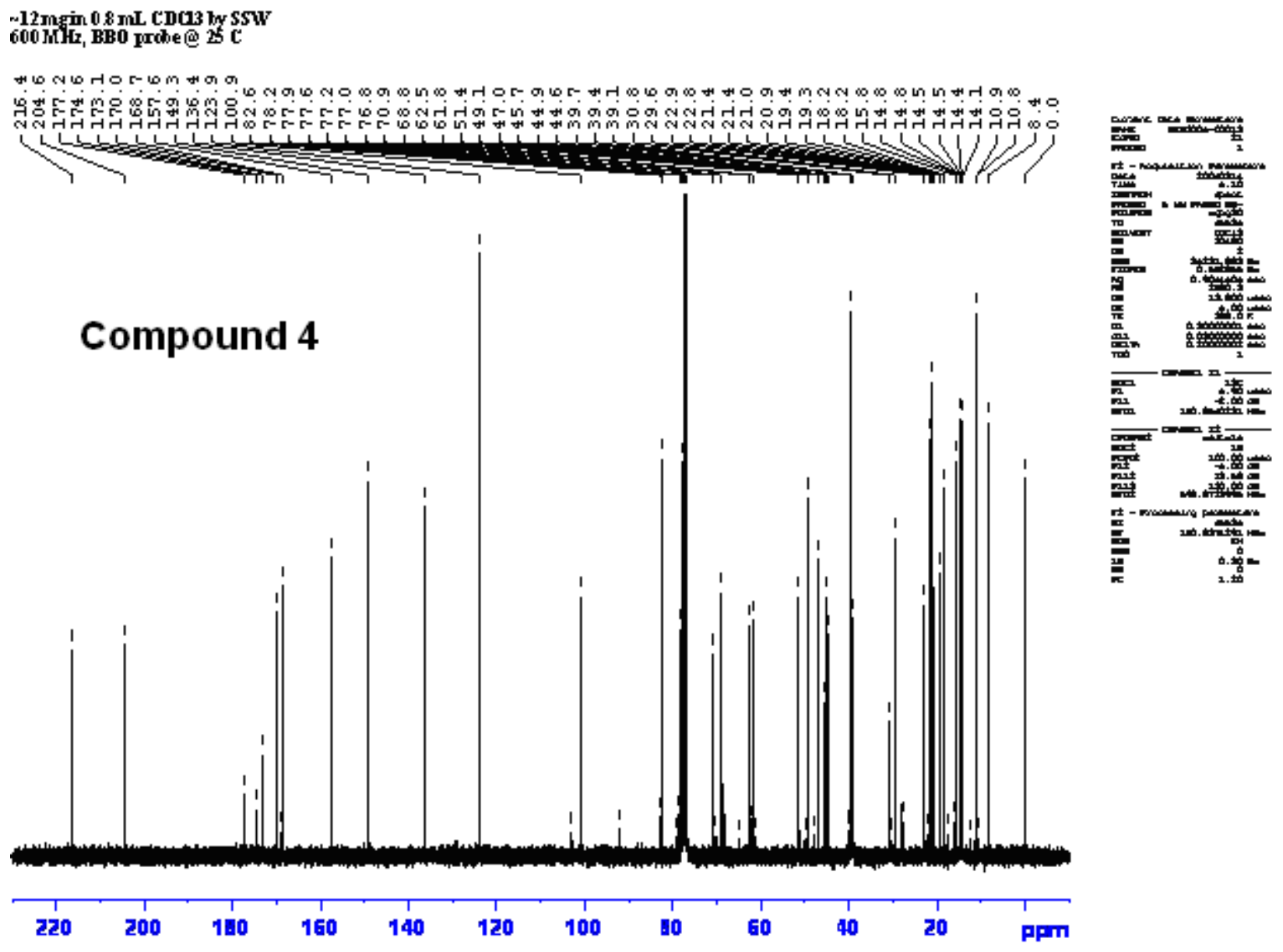




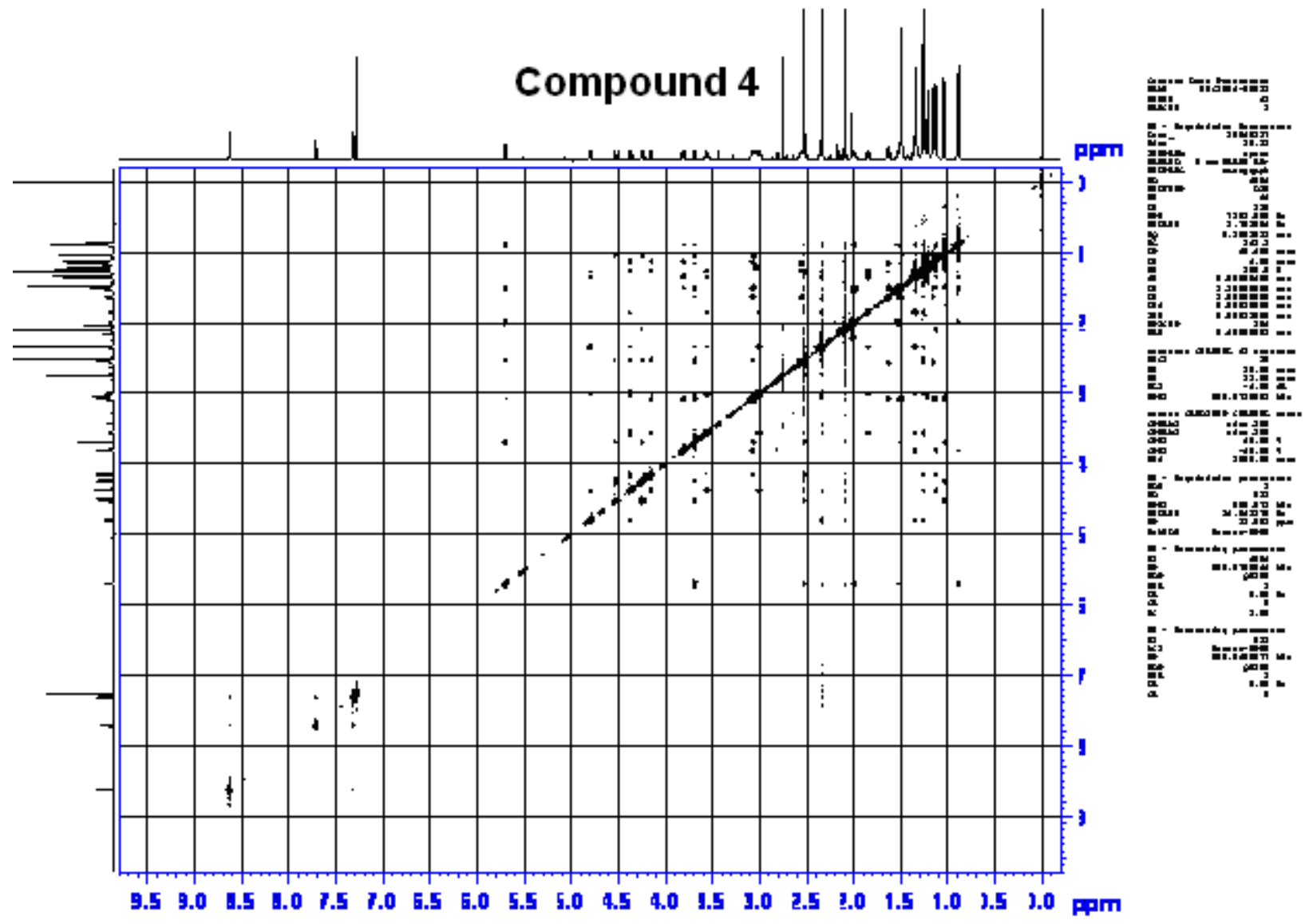


Supporting Information

S42

ROEYY

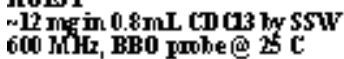
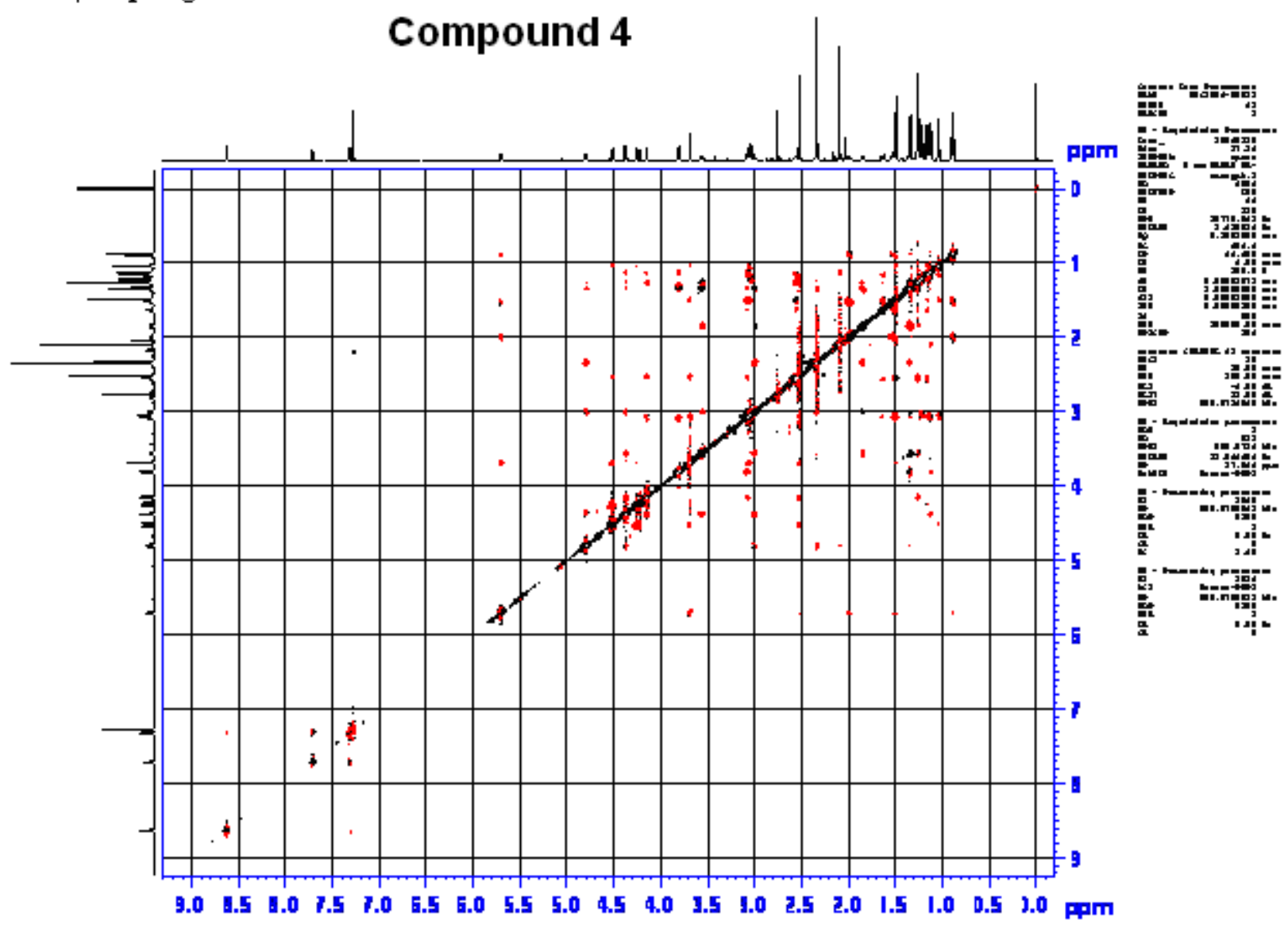